\title{
mGluR5 Positive Allosteric Modulators Facilitate both Hippocampal LTP and LTD and Enhance Spatial Learning
}

\author{
Jennifer E Ayala ${ }^{1,7}$, Yelin Chen ${ }^{2,7,8}$, Jessica L Banko', ${ }^{1,9}$ Douglas J Sheffler', Richard Williams ${ }^{3}$, \\ Alexandra N Telk ${ }^{4}$, Noreen L Watson ${ }^{4}$, Zixiu Xiang', Yongqin Zhang', Paulianda J Jones', \\ Craig W Lindsley ${ }^{1,5,6}$, M Foster Olive ${ }^{4}$ and $P$ Jeffrey Conn ${ }^{*, 1,5}$
}

'Department of Pharmacology, Vanderbilt University Medical Center, Nashville, TN, USA; ${ }^{2}$ Brain Institute, Vanderbilt University Medical Center, Nashville, TN, USA; ${ }^{3}$ Vanderbilt Institute for Chemical Biology, Vanderbilt University Medical Center, Nashville, TN, USA; ${ }^{4}$ Center for Drug and Alcohol Programs, Department of Psychiatry and Behavioral Sciences, Medical University of South Carolina, Charleston, South Carolina, USA; ${ }^{5}$ Vanderbilt Program in Drug Discovery, Vanderbilt University Medical Center, Nashville, TN, USA; ${ }^{6}$ Department of Chemistry, Vanderbilt University Medical Center, Nashville, TN, USA

\begin{abstract}
Highly selective positive allosteric modulators (PAMs) of metabotropic glutamate receptor subtype 5 (mGluR5) have emerged as a potential approach to treat positive symptoms associated with schizophrenia. mGluR5 plays an important role in both long-term potentiation (LTP) and long-term depression (LTD), suggesting that mGluR5 PAMs may also have utility in improving impaired cognitive function. However, if mGluR5 PAMs shift the balance of LTP and LTD or induce a state in which afferent activity induces lasting changes in synaptic function that are not appropriate for a given pattern of activity, this could disrupt rather than enhance cognitive function. We determined the effect of selective mGluR5 PAMs on the induction of LTP and LTD at the Schaffer collateral-CA synapse in the hippocampus. mGluR5-selective PAMs significantly enhanced threshold $\theta$-burst stimulation (TBS)-induced LTP. In addition, mGluR5 PAMs enhanced both DHPG-induced LTD and LTD induced by the delivery of paired-pulse low-frequency stimulation. Selective potentiation of mGluR5 had no effect on LTP induced by suprathreshold TBS or saturated LTP. The finding that potentiation of mGluR5mediated responses to stimulation of glutamatergic afferents enhances both LTP and LTD and supports the hypothesis that the activation of mGluR5 by endogenous glutamate contributes to both forms of plasticity. Furthermore, two systemically active mGluR5 PAMs enhanced performance in the Morris water maze, a measure of hippocampus-dependent spatial learning. Discovery of small molecules that enhance both LTP and LTD in an activity-appropriate manner shows a unique action on synaptic plasticity that may provide a novel approach for the treatment of impaired cognitive function.

Neuropsychopharmacology (2009) 34, 2057-207I; doi:I0.1038/npp.2009.30; published online I8 March 2009
\end{abstract}

Keywords: mGluR5; group I mGluR; synaptic plasticity; LTP; LTD; allosteric potentiator

\section{INTRODUCTION}

Schizophrenia is a complex disorder that includes positive, negative, and cognitive symptoms (Andreasen, 2000). Current medications are partially effective in treating positive symptoms, but largely ineffective in treating cognitive deficits and negative symptoms. Based on this

*Correspondence: Dr PJ Conn, Department of Pharmacology, Vanderbilt University Medical Center, 1215D Light Hall, 2215-B Garland Avenue, Nashville, TN 37232-6600, USA, Tel: + I 615936 2478, Fax: + I 615343 3088, E-mail: jeffrey.conn@vanderbilt.edu

${ }^{7}$ These authors contributed equally

${ }^{8}$ Current address: The Picower Institute for Learning and Memory, Massachusetts Institute of Technology, Cambridge, Massachusetts 02139, USA

${ }^{9}$ Current address: College of Medicine Office of Research, University of South Florida, Tampa, FL 33612, USA

Received 7 October 2008; revised 5 January 2009; accepted 5 February 2009 and serious adverse effects of available antipsychotic agents, there is a critical need for new treatment strategies. Recently, the metabotropic glutamate receptor subtype 5 (mGluR5) has emerged as an exciting target proposed to have efficacy for the treatment of schizophrenia (Marino and Conn, 2002; Conn et al, 2009). This hypothesis is based on evidence suggesting that enhanced signaling through the $\mathrm{N}$-methyl-D-aspartate (NMDA) glutamate receptor may be antipsychotic and that mGluR5 and NMDARs are closely associated signaling partners in forebrain circuits. Activation of mGluR5 potentiates NMDAR function in multiple neuronal populations (Awad et al, 2000; Mannaioni et al, 2001; Pisani et al, 2001; Marino and Conn, 2002) and mGluR5 antagonists or genetic deletion potentiate the psychotomimetic effects of NMDAR antagonists (Henry et al, 2002; Kinney et al, 2003, 2005; Brody et al, 2004a, b; Campbell et al, 2004; Homayoun et al, 2004; Lindsley et al, 2004). Recently, we and others have discovered selective positive allosteric modulators (PAMs) for mGluR5 that have 
robust efficacy in animal models used to predict effectiveness in treating positive symptoms of schizophrenia (O'Brien et al, 2003, 2004; Lindsley et al, 2004, 2006; Kinney et al, 2005; Le Poul et al, 2005; de Paulis et al, 2006; Chen et al, 2007, 2008; Conn et al, 2009; Liu et al, 2008). These mGluR5 PAMs do not activate mGluR5 directly but act at an allosteric site to potentiate activation by glutamate (Chen and Conn, 2008; Conn et al, 2009). These findings provide strong preclinical support for the use of selective activators of mGluR5 as novel antipsychotic agents.

In addition to antipsychotic efficacy, mGluR5 PAMs have the potential to treat impaired cognition in schizophrenia patients. mGluR5 knockout mice have impaired NMDARmediated hippocampal long-term potentiation (LTP) and NMDA-dependent memory tasks (Lu et al, 1997; Jia et al, 1998). Also, the mGluR5 selective antagonist MPEP blocks $\theta$-burst stimulation (TBS)-induced LTP in area CA1 in hippocampal slices (Francesconi et al, 2004; Shalin et al, 2006) and in vivo (Manahan-Vaughan and Braunewell, 2005). Finally, the mGluR $1 / 5$ agonist, DHPG, primes LTP induction (Cohen et al, 1998; Raymond et al, 2000). In addition to regulation of LTP, DHPG induces an NMDARindependent form of long-term depression (LTD) (Gasparini et al, 1999; Huber et al, 2001) and this response is absent in mGluR5 null mice and in hippocampal slices incubated with mGluR5 antagonists (Gasparini et al, 1999; Huber et al, 2001; Faas et al, 2002; Hou and Klann, 2004; Huang et al, 2004; Huang and Hsu, 2006).

In the simplest view, mGluR5 potentiation could enhance synaptic plasticity and thereby enhance some forms of cognitive function. However, previous studies of electrophysiological effects of mGluR5 PAMs relied on potentiation of exogenously applied agonists and it is not clear whether mGluR5 PAMs will enhance the activation of mGluR5 by synaptically released glutamate. Thus, it is critical to determine whether mGluR5-selective PAMs enhance afferent stimulation-induced hippocampal LTP and LTD. Furthermore, if mGluR5 PAMs preferentially augment one form of synaptic plasticity and thereby disturb the LTP/LTD balance, this could disrupt rather than enhance cognitive function. Indeed, recent studies suggest that mutations associated with Fragile X Syndrome (FXS) selectively increase mGluR5-mediated hippocampal LTD (Huber et al, 2002; Bear et al, 2004; Nosyreva and Huber, 2006), although having no effect (Godfraind et al, 1996; Paradee et al, 1999; Li et al, 2002) or depressing hippocampal LTP (Lauterborn et al, 2007). This preferential enhancement of mGluR-LTD is thought to be a primary change contributing to cognitive disruption associated with FXS. Thus, we performed a series of studies to determine the effects of mGluR5 PAMs on hippocampal LTP and LTD.

We report that selective mGluR5 PAMs enhance afferent stimulation-induced LTP and LTD at the SC-CA1 synapse. Importantly, these compounds enhance both forms of synaptic plasticity while maintaining the normal patterns of presynaptic activity required to induce each, which may provide an ideal profile for agents that are used to improve some forms of cognitive function. In addition, we demonstrate that these compounds improve performance in a model of hippocampus-dependent spatial learning. This builds on studies suggesting that mGluR5 PAMs have potential utility as novel antipsychotic agents and provides direct support for the hypothesis that mGluR5 PAMs may also enhance hippocampal-dependent cognitive function.

\section{MATERIALS AND METHODS}

\section{Materials}

4-Nitro- $N$-(1,3-diphenyl-1H-pyrazol-5-yl)benzamide (VU29) was synthesized as outlined in detail by de Paulis et al (2006). 5MPEP was synthesized as detailed by Rodriguez et al (2005). CDPPB was synthesized as detailed by Lindsley et al (2004). D-AP5, DHPG, glutamate, U0126, and PP 1 were purchased from Tocris (Ellisville, MO). ADX47273 was synthesized as outlined in the Supplementary Information section.

\section{Animals}

All animals used in these studies were cared for in accordance with the National Institutes of Health Guide for the Care and Use of Laboratory Animals. Experimental protocols were in accordance with all applicable guidelines regarding the care and use of animals. Animals were housed in an Association for Assessment and Accreditation of Laboratory Animal Care (AALAC) International approved facility with free access to food and water. All efforts were made to minimize animal suffering and to reduce the number of animals used.

\section{Measurement of Phosphoinositide Hydrolysis in Hippocampal Slices}

Agonist-induced phosphoinositide (PI) hydrolysis was measured in rat hippocampal slices using a modification of the method outlined by Berridge et al (1982) as described previously (Berridge et al, 1982; Conn and Sanders-Bush, 1986). Briefly, cross-chopped $(350 \mu \mathrm{M} \times 350 \mu \mathrm{M})$ slices of male (6-9 weeks) Sprague-Dawley rat hippocampus were incubated with $95 \% \quad \mathrm{O}_{2} / 5 \% \quad \mathrm{CO}_{2}$ bubbled Krebs buffer $\left(108 \mathrm{mM} \mathrm{NaCl}, 4.7 \mathrm{mM} \mathrm{KCl}, 1.2 \mathrm{mM} \mathrm{MgSO}_{4}, 1.2 \mathrm{mM}\right.$ $\mathrm{KH}_{2} \mathrm{PO}_{4}, 2.5 \mathrm{mM} \quad \mathrm{CaCl}_{2}, 25 \mathrm{mM} \mathrm{NaHCO}_{3}$ and $10 \mathrm{mM}$ glucose). The tissue was allowed to recover for $30 \mathrm{~min}$ with shaking at $37^{\circ} \mathrm{C}$. Following recovery, the tissue was combined, washed with warm Krebs buffer, and $25 \mu \mathrm{l}$ of gravity packed slices were incubated with $175 \mu \mathrm{l}$ Krebs containing $0.5 \mu \mathrm{Ci}\left[{ }^{3} \mathrm{H}\right]$ myo-inositol for $45 \mathrm{~min}$. VU-29 or vehicle controls were added and incubated for $15 \mathrm{~min}$, followed by the addition of $10 \mathrm{mM} \mathrm{LiCl}$ and incubated for an additional $15 \mathrm{~min}$. Finally, DHPG was added and followed by an additional $45 \mathrm{~min}$ incubation. The reaction was terminated by the addition of $900 \mu \mathrm{l}$ of chloroform/ methanol $(1: 2)$. The aqueous and organic phases were separated by the addition of $300 \mu \mathrm{l}$ chloroform and $300 \mu \mathrm{l}$ water, vortexing, and allowing the phases to separate by gravity. The aqueous phase was added to anion exchange columns (AG 1-X8 Resin, 100-200 mesh, formate form, BIO-RAD) and $\left[{ }^{3} \mathrm{H}\right]$ inositol phosphates were eluted and measured by liquid scintillation counting. 


\section{Cell Culture}

Secondary rat cortical astrocytes were prepared as previously described (Peavy et al, 2001; Zhang et al, 2005; Chen et al, 2007). In brief, neocortices from 2- to 4-day-old SpragueDawley rat pups were dissected and dissociated in DMEM by trituration with 1-ml pipette tips. The cells were then centrifuged and resuspended in DMEM (containing $1 \mathrm{mM}$ sodium pyruvate, $2 \mathrm{mM}$ L-glutamine, and PenStrep $(100 \mathrm{U} / \mathrm{ml}$ penicillin and $0.1 \mathrm{mg} / \mathrm{ml}$ streptomycin; Invitrogen, Carlsbad, CA)) supplemented with $10 \%$ FBS in T75 tissue culture flasks; the medium was changed the next day. Cell cultures were maintained at $37^{\circ} \mathrm{C}$ in an atmosphere of $95 \%$ air, $5 \% \mathrm{CO}_{2}$ for 6-8 days. Cells were shaken overnight (280-310 r.p.m.) to remove oligodendrocytes and microgliocytes. For ERK1/2 phosphorylation assay, the cells were then trypsinized and replated into poly-D-lysine-precoated 12 -well plates at a density of about $6 \times 10^{6}$ cells per well in full DMEM with $10 \%$ FBS. The second day, the medium was switched to full DMEM with G-5 supplement (Invitrogen) containing epidermal growth factor $(10 \mathrm{ng} / \mathrm{ml})$, basic fibroblast growth factor $(5 \mathrm{ng} / \mathrm{ml})$, insulin $(5 \mu \mathrm{g} / \mathrm{ml})$, and other factors. The cells were nearly confluent within 2 days and resembled the polygonal astrocytic appearance in vivo. Three days after the addition of G-5 supplement and $20 \mathrm{~h}$ before experiments, the medium was aspirated, and the cells were washed three times with $1 \times$ Hanks' balanced salt solution, and $1 \mathrm{ml}$ of glutamine-free DMEM was added to each well.

\section{Cell-Based Calcium Fluorescence Measurement}

Rat mGluR1d was transfected into HEK293A cells using Lipofectamine as described earlier (Chen et al, 2007). Rat mGluR2 and human mGluR4 were co-expressed with $\mathrm{G}_{\mathrm{qi}}$, which enables coupling to the calcium mobilization as described earlier (Galici et al, 2006). Cells were loaded with calcium-sensitive dye according to the manufacturer's instructions (Calcium 3 kit; Molecular Devices, Sunnyvale, CA) after incubation in glutamate/glutamine-free medium (DMEM and $10 \%$ dialyzed fetal bovine serum) for $5 \mathrm{~h}$. Compound $\mathrm{A}(1 \mathrm{ml})$ from Calcium 3 kit was dissolved in $20 \mathrm{ml}$ of $1 \times$ Hanks' balanced salt solution (HBSS; Invitrogen) containing $2.5 \mathrm{mM}$ probenecid (Sigma), adjusted to $\mathrm{pH}$ 7.4. Cells were loaded for $50 \mathrm{~min}$ at $37^{\circ} \mathrm{C}$ under an atmosphere of $5 \%$ carbon dioxide. Dye was then carefully removed, and cells were washed with HBSS containing probenecid. Cells were maintained in the same buffer at room temperature for the following assay. For calcium fluorescence measurement of rat cortical astrocytes, allosteric modulators were manually added $5 \mathrm{~min}$ before the addition of an agonist. The agonist was added at a rate of $52 \mu \mathrm{l} / \mathrm{s}$, and calcium flux was measured using Flexstation II (Molecular Devices) at $25^{\circ} \mathrm{C}$. All of the peaks of the calcium response were normalized to the maximum response to a saturated dose of glutamate $(10 \mu \mathrm{M})$. The submaximal concentration $\left(\mathrm{EC}_{20}\right.$ value) of glutamate was determined for each separate experiment, allowing for a response varying from 10 to $30 \%$ of the maximum peak.

\section{ERK1/2 Phosphorylation Assay}

On the day of each assay, cells were first treated with $\mathrm{CDPPB}$, and then stimulated with the agonist. At the end of stimulation, medium containing the drug was aspirated, and $200 \mu \mathrm{l}$ of ice-cold lysis buffer (containing $50 \mathrm{mM}$ Tris$\mathrm{HCl}, 50 \mathrm{mM} \mathrm{NaCl}, 5 \mathrm{mM}$ EDTA, $10 \mathrm{mM}$ EGTA, $1 \mathrm{mM}$ $\mathrm{Na}_{3} \mathrm{VO}_{4}, 2 \mathrm{mM} \mathrm{Na} \mathrm{P}_{4} \mathrm{P}_{2} \mathrm{O}_{7} \cdot 10 \mathrm{H}_{2} \mathrm{O}, 4 \mathrm{mM}$ magnesium paranitrophenyl phosphate, and $1 \mathrm{mM}$ phenylmethylsulfonyl fluoride plus $10 \mu \mathrm{g} / \mathrm{ml}$ leupeptin, and $2 \mu \mathrm{g} / \mathrm{ml}$ aprotinin) was added to each well. Cells were frozen at $-80^{\circ} \mathrm{C}$ and underwent three thaw and refreeze cycles. Cells were scraped into clean tubes, the samples were centrifuged, and the supernatant was collected. Equal amounts of supernatant from each sample were mixed with $3 \times$ lithium dodecyl sulfate sample buffer, subjected to SDS-polyacrylamide gel electrophoresis, and transferred to nitrocellulose membranes. Membranes were first blocked and then stained with primary rabbit anti-p44/42 mitogen-activated protein kinase (ERK1/2) polyclonal antibody mixed with primary mouse anti-phospho-p44/42 mitogen-activated protein kinase (phospho-ERK1/2) monoclonal antibody (Cell Signaling Technology Inc. Beverly, MA). After washing three times, membranes were subsequently stained with fluorescent dye Alexa Fluor 680-conjugated secondary goat antimouse IgG $(\mathrm{H}+\mathrm{L})$ (Invitrogen) mixed with fluorescent dye IRDye800-conjugated secondary goat anti-rabbit IgG ( $\mathrm{H}+$ L) (Rockland, Gilbertsville, PA). Membranes were scanned using Odyssey Imaging System (LI-COR, Lincoln, NE). ERK1/2 phosphorylation (phosphorylated ERK1/2) is first normalized to total ERK1/2 and then expressed as percentage of maximal response or -fold above control.

\section{Extracellular Field Potential Recordings}

Young adult (6-9 weeks) male Sprague-Dawley rats (Charles River, Wilmington, MA) were anesthetized with isoflorane, decapitated and the brains were quickly removed and submerged into ice-cold cutting solution (in mM: 110 sucrose, $60 \mathrm{NaCl}, 3 \mathrm{KCl}, 1.25 \mathrm{NaH}_{2} \mathrm{PO}_{4}, 28 \mathrm{NaHCO}_{3}, 5$ glucose, $0.6(+)$-sodium-L-ascorbate, $0.5 \mathrm{CaCl}_{2}, 7 \mathrm{MgCl}_{2}$ ) continuously bubbled with $95 \% \mathrm{O}_{2} / 5 \% \mathrm{CO}_{2}$. The brains were then hemisected and $400 \mu \mathrm{m}$ transverse slices were made using a vibratome (Leica VT100S). Individual hippocampi were removed from the slice and transferred to a room temperature mixture containing equal volumes of cutting solution and artificial cerebrospinal fluid (aCSF; in mM: $125 \mathrm{NaCl}, 2.5 \mathrm{KCl}, 1.25 \mathrm{NaH}_{2} \mathrm{PO}_{4}, 25 \mathrm{NaHCO}_{3}, 25$ glucose, $2 \mathrm{CaCl}_{2}, 1 \mathrm{MgCl}_{2}$ ) where they were allowed to equilibrate for $30 \mathrm{~min}$. The hippocampi were then placed into an interface chamber perfused with oxygenated aCSF $(1.5-2 \mathrm{ml} / \mathrm{min})$ for at least $1.5 \mathrm{~h}$ at $31^{\circ} \mathrm{C}$. Bipolar-stimulating electrodes were placed in the stratum radiatum near the CA3-CA1 border in order to stimulate the Schaffer collaterals. Recording electrodes were pulled with a Flaming/Brown micropipette puller (Sutter Instruments, CA) to a resistance of 3-5M $\mathrm{M}$, filled with aCSF and placed in the stratum radiatum of area CA1. Field potential recordings were acquired using either a Microelectrode AC Amplifier Model 1800 (A-M Systems) or Patch Clamp PC-505B (Warner Instruments) amplifier and pClamp 9.2 software. Input-output curves were generated to determine the stimulus intensity that produced $40-50 \%$ of the maximum response before each experiment, which was used as the baseline stimulation. Baseline stimulation was applied at $0.05 \mathrm{~Hz}$. Drugs were diluted to the appropriate concentrations 
in either DMSO $(<0.1 \%)$ or aCSF. Threshold LTP was induced by one train of TBS (nine bursts of four pulses at $100 \mathrm{~Hz} ; 230 \mathrm{~ms}$ interburst interval). Saturated LTP was induced by four trains of $10 \mathrm{~Hz}$ TBS (nine bursts of four pulses at $100 \mathrm{~Hz}, 100 \mathrm{~ms}$ interburst interval). Chemically induced mGluR-LTD was induced by the application of DHPG $(25-75 \mu \mathrm{M})$ for $10 \mathrm{~min}$. Synaptically evoked mGluRLTD was induced by paired-pulse low-frequency stimulation (PP-LFS) consisting of 900 pairs of stimuli (50-ms interstimulus interval) delivered at $1 \mathrm{~Hz}$ for $15 \mathrm{~min}$ and performed in aCSF containing in mM: $124 \mathrm{NaCl}, 5 \mathrm{KCl}, 1.25$ $\mathrm{NaH}_{2} \mathrm{PO}_{4}, 26 \mathrm{NaHCO}_{3}, 10$ glucose, $2 \mathrm{CaCl}_{2}, 1 \mathrm{MgCl}_{2}$ (Kemp and Bashir, 1999; Huber et al, 2000). Synaptically evoked NMDA receptor-dependent LTD was induced by lowfrequency stimulation (LFS) consisting of 900 stimuli delivered at $1 \mathrm{~Hz}$ for $15 \mathrm{~min}$ in the same aCSF used in the PP-LFS studies. Sampled data was analyzed offline using Clampfit 9.2. Three sequential fEPSPs were averaged and their slopes calculated. All fEPSP slopes were normalized to the average slope calculated during the predrug period (percent of baseline). Statistical significance was analyzed using GraphPad Prism and the Student's unpaired t-test unless otherwise noted.

\section{Whole-Cell Patch-Clamp Recordings}

18 to 24-day-old Sprague-Dawley rats were anesthetized with isoflorane, decapitated, and the brains were quickly removed and submerged into ice-cold choline chloride replacement solution (in mM: 126 Choline chloride, $2.5 \mathrm{KCl}$, $8 \mathrm{MgSO}_{4}, 1.3 \mathrm{MgCl}_{2}, 1.2 \mathrm{NaH}_{2} \mathrm{PO}_{4}, 10$ glucose, $26 \mathrm{NaHCO}_{3}$ ). The brains were then hemisected and $300 \mu \mathrm{m}$ transverse slices were made using a vibratome (Vibratome 3000 Plus). Individual hippocampi were removed from the slice and transferred to a holding chamber containing artificial cerebrospinal fluid (aCSF; in mM: $130 \mathrm{NaCl}, 3.5 \mathrm{KCl}, 1.25$ $\mathrm{NaH}_{2} \mathrm{PO}_{4}, 24 \mathrm{NaHCO}_{3}, 10$ glucose, $1.5 \mathrm{CaCl}_{2}, 1.5 \mathrm{MgCl}_{2}$ ), incubated at $37^{\circ} \mathrm{C}$ for $30 \mathrm{~min}$, and then equilibrated at room temperature for at least $45 \mathrm{~min}$ before recording. In all experiments, $5 \mu \mathrm{M}$ glutathione and $500 \mu \mathrm{M}$ pyruvate were included in the choline chloride buffer and in the holding chamber ACSF. During recordings, slices were maintained fully submerged on the stage of a brain slice chamber perfused with heated $\left(32^{\circ} \mathrm{C}\right)$ and oxygenated ACSF at $2 \mathrm{ml} /$ min. CA1 pyramidal neurons were visualized with an Olympus BX51WI upright microscope (Olympus, Lake Success, NY) coupled with a $\times 40$ water immersion objective and Hoffman optics. Borosilicate glass pipettes were pulled using a Flaming/Brown micropipette puller (Sutter Instruments, CA) to produce patch electrode resistances of 2-4 M $\Omega$ when filled with an intracellular solution containing (in $\mathrm{mM}$ ): $135 \mathrm{~K}-\mathrm{MeSO}_{4}, 5 \mathrm{NaCl}, 1$ $\mathrm{MgCl}_{2}, 0.025 \mathrm{CaCl}_{2}, 10$ HEPES, 0.6 EGTA, 2 ATP, $0.2 \mathrm{GTP}$. The voltage-clamp signal was low pass-filtered at $2 \mathrm{kHz}$, digitized at $10 \mathrm{kHz}$, and acquired using a Clampex9.2/ DigiData 1332 system (Molecular Devices, Sunnyvale, CA).

\section{Morris Water Maze}

CDPPB was suspended in a vehicle consisting of $20 \% \mathrm{w} / \mathrm{v} 2-$ hydroxypropyl-b-cyclodextrin. ADX47273 was dissolved in a vehicle consisting of $10 \% \mathrm{v} / \mathrm{v}$ Tween-80. All injections were made through the intraperitoneal (i.p.) route in a volume of $1 \mathrm{ml} / 100 \mathrm{~g}$ body weight. The maze apparatus consisted of a $90 \mathrm{~cm}$ diameter tub filled with $23 \pm 1^{\circ} \mathrm{C}$ water that covered a $6 \mathrm{~cm}$ diameter submerged platform. Visual cues were placed above the rim of the tub to facilitate spatial navigation. The water was made opaque by the addition of dilute nontoxic white paint. Mice were injected i.p. with the mGluR5-positive allosteric modulators CDPPB $(10 \mathrm{mg} / \mathrm{kg})$, or ADX47273 $(10 \mathrm{mg} / \mathrm{kg})$, or their corresponding vehicles 20 min before testing. A total of four test trials (each separated by $5 \mathrm{~min}$ ) were conducted on each day for a total of 13 days, with four separate starting points utilized for each trial. The sequence of the starting point location was randomized on each day of testing. Latency to reach the platform was recorded for each trial, and a maximum swim time was set at $60 \mathrm{~s}$ per trial. If the animal failed to reach the platform on any of the trials within $60 \mathrm{~s}$, it was then gently guided by the experimenter to the platform and given a score of $60 \mathrm{~s}$. Acquisition criteria were considered to be obtained when the latency to reach the platform was $\leqslant 15 \mathrm{~s}$ on each of the four consecutive trials. On the day following the last day of testing, a probe trial was conducted in which the platform was removed and time spent in the quadrant where the platform was previously located was recorded for each of the four trials. Drugs were not administered on the day of the probe trial.

\section{RESULTS}

\section{Allosteric Modulators of mGluR5 have Predicted Effects on Phosphoinositide Hydrolysis and ERK1/2 Phosphorylation in Native Systems}

Group I mGluRs signal through the activation of $\mathrm{G}_{\mathrm{q}}$ proteins leading to the downstream effects of $P K C$ activation, PI hydrolysis and increased intracellular calcium release (Conn and Pin, 1997). Both the mGluR5 PAMs and the neutral allosteric site ligand, 5MPEP, have been previously characterized using cell lines and recombinantly expressed mGluRs (Rodriguez et al, 2005; Chen et al, 2007). However, prior to using these compounds for studies of the role of mGluR5 in hippocampal LTP and LTD, we verified their ability to modulate mGluR5-mediated increases in PI hydrolysis in hippocampal slices. In agreement with previous studies (Sacaan et al, 1998; Gasparini et al, 1999; Johnson et al, 1999), the group I mGluR agonist, DHPG induced a concentration-dependent increase in PI hydrolysis in rat hippocampal slices (Figure 1a). Consistent with its effect in cell lines, the mGluR5 PAM, VU-29 had no effect on baseline PI hydrolysis but induced a leftward shift in the DHPG concentration response curve (CRC) and enhanced the maximum response to DHPG (Figure 1a; DHPG alone, $\mathrm{EC}_{50}=8 \pm 1.6 \mu \mathrm{M} ; \mathrm{DHPG}+\mathrm{VU}-29, \mathrm{EC}_{50}=4.5 \pm 1 \mu \mathrm{M}, \max$ response $=138 \pm 12 \%, n=5)$. We then determined the effect of VU-29 on the response to a single concentration of DHPG that induced an approximate $\mathrm{EC}_{20}$ PI hydrolysis response. DHPG $(3 \mu \mathrm{M})$ induced a small but significant increase in PI hydrolysis compared with vehicle control (Figure 1b; $p<0.0001, n=3$ ), which was significantly potentiated by VU-29 $(5 \mu \mathrm{M})$ (Figure $1 \mathrm{~b} ; p<0.001, n=3$ ). $5 \mathrm{MPEP}$ was previously described as a neutral allosteric site ligand at mGluR5 that is capable of selectively inhibiting the 

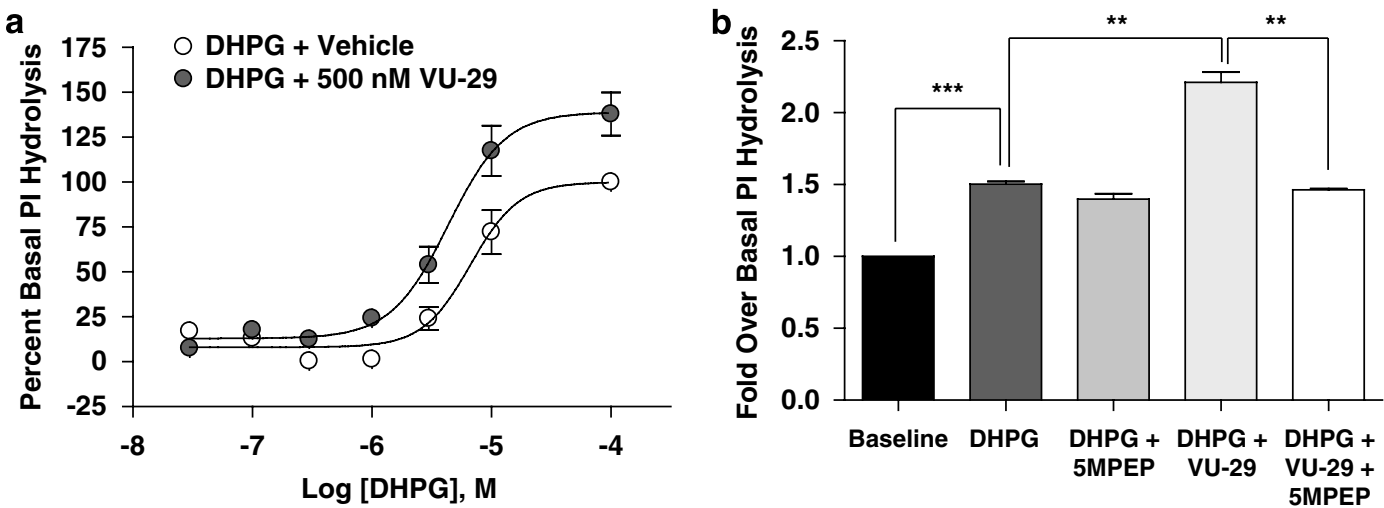

Figure I VU-29 potentiates DHPG-induced increases in PI hydrolysis in rat hippocampal slices. (a) $500 \mathrm{nM} \mathrm{VU-29}$ induced a significant leftward shift in the concentration response curve of DHPG-induced PI hydrolysis in rat hippocampal slices. In the presence of VU-29 the EC 50 of DHPG was $4.5 \pm 1 \mu M$, compared with $8 \pm 1.6 \mu \mathrm{M}$ in the absence of $\mathrm{VU}-29$. In addition, the maximum response was enhanced by $38 \pm 13 \%$. (b) $3 \mu \mathrm{M}$ DHPG increased baseline PI hydrolysis, which was significantly enhanced by pre-incubation of $5 \mu \mathrm{MVU}-29$ but not altered by $100 \mu \mathrm{M} 5 \mathrm{MPEP}$ in rat hippocampal slices. $5 \mathrm{MPEP}$ blocked the potentiation caused by $\mathrm{VU}-29$. ( $n=5$, experiments performed in triplicate). Error bars represent SEM. $* * * * 1<0.000 \mathrm{I}, * * * 0.00 \mathrm{I}$.

effects of mGluR5 PAMs, such as VU-29 (Rodriguez et al, 2005; Chen et al, 2007, 2008). Consistent with this, 5MPEP $(100 \mu \mathrm{M})$ had no effect on the phosphoinositide hydrolysis response to DHPG, but specifically inhibited the ability of VU-29 to potentiate the PI hydrolysis response (Figure 1b; $p<0.001, n=3)$.

In addition, previous studies have demonstrated that multiple mGluR5 PAMs, including CPPHA and ADX47273 potentiate DHPG-induced increases in ERK1/2 phosphorylation in hippocampal slices and cortical astrocytes (Zhang et al, 2005; Liu et al, 2008). We now determined the effect of the VU-29 analog, CDPPB, on ERK1/2 phosphorylation in cortical astrocytes to confirm reports that mGluR5 PAMs belonging to this structural class also potentiate coupling of mGluR5 to this signaling pathway. As with the other mGluR5 PAMs, CDPPB induced a robust potentiation of DHPG-induced increases in ERK1/2 phosphorylation in astrocytes (see Supplementary Figure S1). Finally, we have previously shown that CPPHA potentiates mGluR5 regulation of NMDA receptor currents in hippocampal pyramidal cells (O'Brien et al, 2004) and that VU-29 and CDPPB selectively potentiate mGluR5-mediated responses in acute brain slices in the subthalamic nucleus although having no effect on mGluR1-mediated responses in the substantia nigra pars reticulata (Chen et al, 2007). Together, these data provide strong evidence that mGluR5 PAMs potentiate mGluR5 responses in multiple native systems.

\section{VU-29 Potentiates Threshold TBS-Induced LTP in Rat Hippocampal CA1 Region}

To determine the effect of VU-29 on induction of LTP, extracellular field excitatory postsynaptic potentials (fEPSPs) were recorded from the dendritic layer of CA1 following stimulation of the Schaffer collaterals (SC-CA1 synapse). TBS is a common stimulus protocol used to elicit robust LTP at this synapse (Larson and Lynch, 1989). Consistent with multiple previous reports, stimulation of SC afferents using a standard TBS protocol-induced robust LTP at the SC-CA1 synapse (Figure $2 \mathrm{a} ; 183 \pm 10 \%$ of baseline at 45 min post TBS, $n=6$ ). In contrast, stimulation with a modified TBS protocol, termed threshold TBS, using one train of a lower frequency of stimulus bursts (see Materials and methods) induced only a slight potentiation of fEPSPs (Figure $2 \mathrm{~b} ; 115 \pm 6 \%$ of baseline at 45 -min post threshold TBS, $n=10$ ). Threshold TBS provides an ideal protocol that can be used to determine whether selective potentiation of mGluR5 with VU-29 can enhance LTP in response to a submaximal stimulus. Application of $500 \mathrm{nM}$ VU-29 had no effect on the baseline synaptic responses as measured by fEPSP slope (Figure 2c; $99.6 \pm 6 \%$ of baseline, $n=8$ ). Interestingly, this same threshold TBS protocol induced robust LTP when delivered to slices preincubated with VU$29(500 \mathrm{nM})$ for $20 \mathrm{~min}$ prior to delivery of the stimulus train (Figure $2 \mathrm{~d} ; 152 \pm 8 \%$ of baseline at 45 -min post TBS; $p<0.05$, $n=10)$. VU-29 did not alter paired-pulse facilitation, fiber volley amplitude, or input-output curves compared with vehicle controls (see Supplementary Figure S2). In addition, VU-29 did not alter passive membrane properties of CA1 pyramidal cells when recorded in whole-cell patch-clamp mode including input resistance, action potential firing or membrane potential (see Supplementary Figure S3).

Importantly, 5MPEP $(100 \mu \mathrm{M})$ completely blocked the ability of VU-29 to enhance LTP induced by threshold TBS (Figure 3a; $92 \pm 14 \%$ of baseline at $45-\mathrm{min}$ post TBS; $p>0.05, n=8$ ), suggesting that the action of VU-29 is due to actions of this compound on mGluR5. In contrast, 5MPEP $(100 \mu \mathrm{M})$ had no effect on the induction of LTP by a standard suprathreshold TBS protocol (Figure 3b; $192 \pm 19 \%$ of baseline at $45 \mathrm{~min}$ post TBS in the absence of 5 MPEP, $n=8 ; 185 \pm 13 \%$ of baseline $45-$ min post TBS in the presence of $5 \mathrm{MPEP}, n=8$ ) or by the threshold TBS protocol (Figure 3c;133 $\pm 14 \%$ of baseline at $45-$ min post TBS in the absence of 5 MPEP, $n=4 ; 128.3 \pm 11 \%$ of baseline at $45-\mathrm{min}$ post TBS in the presence of $5 \mathrm{MPEP}, n=5$ ). This suggests that the effect of 5MPEP is specific to the VU-29 potentiation and excludes the possibility that 5MPEP inhibited LTP induction through blockade of signaling components other than mGluR5 that are required for LTP induction.

Induction of LTP in the Presence of VU-29 is Dependent on Activation of NMDA Receptors and an Src-Family Tyrosine Kinase

Previous studies suggest that induction of LTP at the SCCA1 synapse by suprathreshold TBS is dependent on 

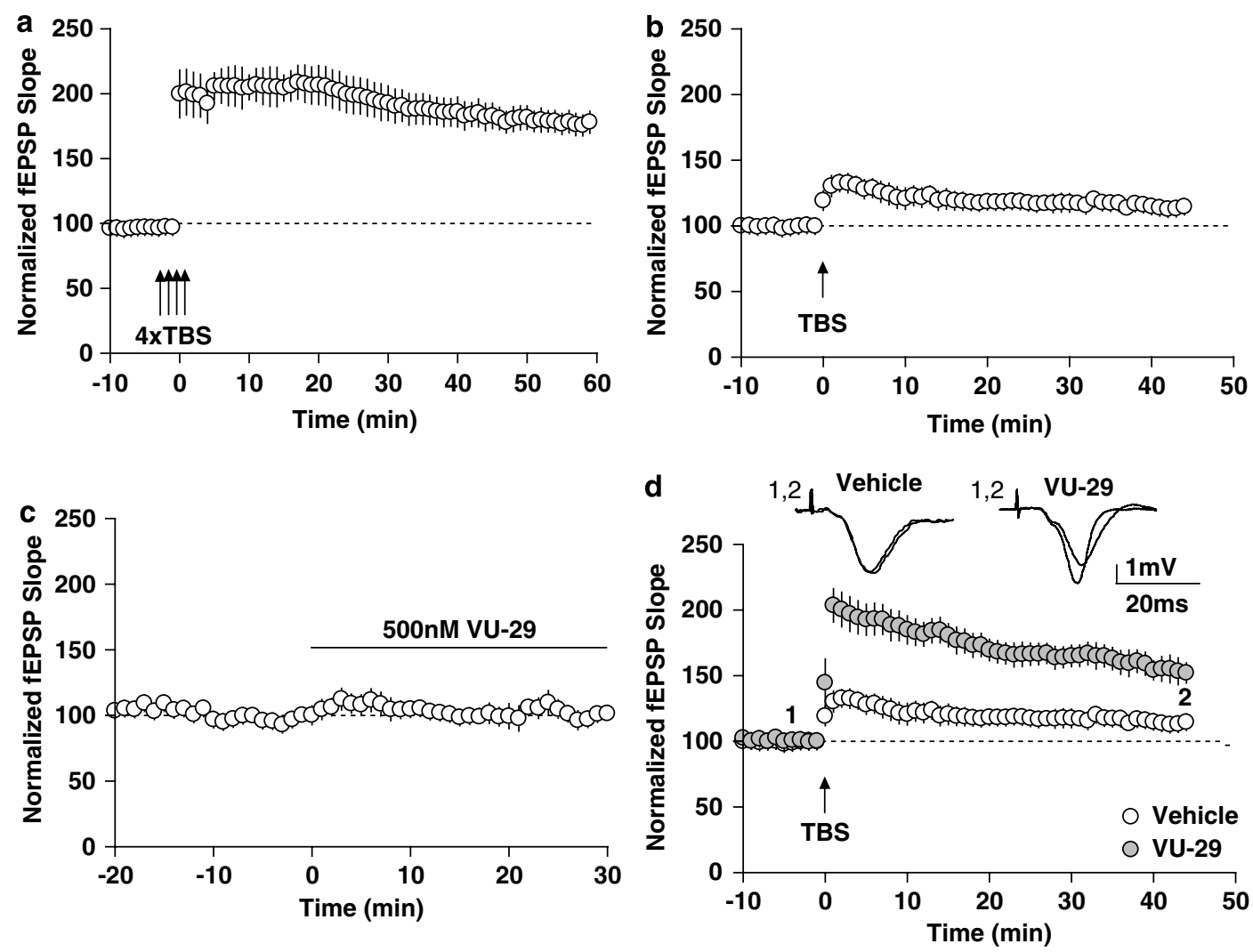

Figure 2 The mGluR5 allosteric potentiator VU-29 facilitates the induction of LTP in area CAI of the hippocampus. (a) Four trains of I0 Hz TBS induced a long lasting potentiation of the fEPSP slope at the SC-CAI synapse. (b) Threshold TBS induced a slight potentiation of the fEPSP slope. (c) A 30-min incubation of $500 \mathrm{nM} \mathrm{VU-29} \mathrm{did} \mathrm{not} \mathrm{alter} \mathrm{the} \mathrm{baseline} \mathrm{fEPSP} \mathrm{slope} \mathrm{recorded} \mathrm{in} \mathrm{the} \mathrm{rat} \mathrm{hippocampal} \mathrm{CAI} \mathrm{region}(n=8)$. (d) In control slices, threshold TBS induced a slight potentiation of fEPSP. In the presence of VU-29 (20-min pre-incubation) the same stimulation induced a significant potentiation ( $n=12$; $p<0.05)$. Error bars represent SEM.

activation of NMDA receptors (Collingridge and Bliss, 1995). In addition, it has been shown that activation of mGluR5 with DHPG potentiates NMDA receptor currents (Collingridge and Bliss, 1995; Doherty et al, 1997, 2000; Jia et al, 1998; Awad et al, 2000; Mannaioni et al, 2001; Gerber et al, 2007) and that this potentiation occurs in a G-protein, protein kinase $\mathrm{C}$, and Src-family kinase-dependent manner (Benquet $e t$ al, 2002). Furthermore, we previously reported that mGluR5 PAMs potentiate DHPG-induced enhancement of NMDA receptor currents recorded from CA1 pyramidal cells (O'Brien et al, 2004). Thus, it is possible that potentiation of synaptically activated mGluR 5 by VU-29 enhances the induction of normal NMDA receptor-dependent LTP. However, it is also possible that VU-29 leads to induction of a distinct form of LTP that is independent of NMDA receptor activation. To determine whether threshold TBS-LTP is dependent on NMDA receptor activation and Src-family kinases in VU-29-treated slices, we determined the effects of the NMDA receptor antagonist, D-AP5 (Figure $4 \mathrm{a}$ and $\mathrm{b}$ ), and the Src-family kinase inhibitor, PP 1 (Figure $4 \mathrm{~b}$ ), on TBS-induced LTP in the presence of VU-29. D-AP5 $(50 \mu \mathrm{M})$ and PP $1(20 \mu \mathrm{M})$ completely blocked the induction of LTP by the combination of VU-29 and threshold TBS (Figure 4; D-AP5: $106.4 \pm 9 \%$ of baseline, $n=4$; PP 1: $98.5 \pm 4 \%$ of baseline, $n=7)$.

\section{VU-29 Potentiates Chemically Induced mGluR-LTD}

It is well established that activation of mGluR5 by exogenous agonist application induces LTD of synaptic transmission at the SC-CA1 synapse, phenomenon referred to as mGluR-LTD (Palmer et al, 1997; Camodeca et al, 1999; Fitzjohn et al, 1999; Huber et al, 2000, 2001; Kemp and Bashir, 2001; Faas et al, 2002; Tan et al, 2003; Nosyreva and Huber, 2005; Huang and Hsu, 2006; Volk et al, 2006; Kumar and Foster, 2007). Based on the clear role of mGluR5 in mGluR-LTD, we were somewhat surprised that selective potentiation of mGluR5 induced such a robust increase in threshold TBS-LTP and might have expected the opposite result. In light of this, we performed a series of studies to determine whether selective potentiation of mGluR5 would also enhance mGluR-LTD induced by application of the group I mGluR agonist DHPG. Before determining the effect of VU-29 on LTD, we established a concentration of DHPG that resulted in a significant but modest LTD response to ensure that we were working in a submaximal DHPG concentration range. At $75 \mu \mathrm{M}$ DHPG induced robust LTD (Figure $5 \mathrm{a} ; 49.1 \pm 7.8 \%$ of baseline $80-90 \mathrm{~min}$ following washout of DHPG, $n=4$ ). A similar, though somewhat smaller LTD response was elicited with the application of $50 \mu \mathrm{M}$ DHPG (Figure 5a; $68.9 \pm 5.5 \%$ of baseline, $n=5$ ). In contrast, $25 \mu \mathrm{M}$ DHPG resulted in only a slight depression 

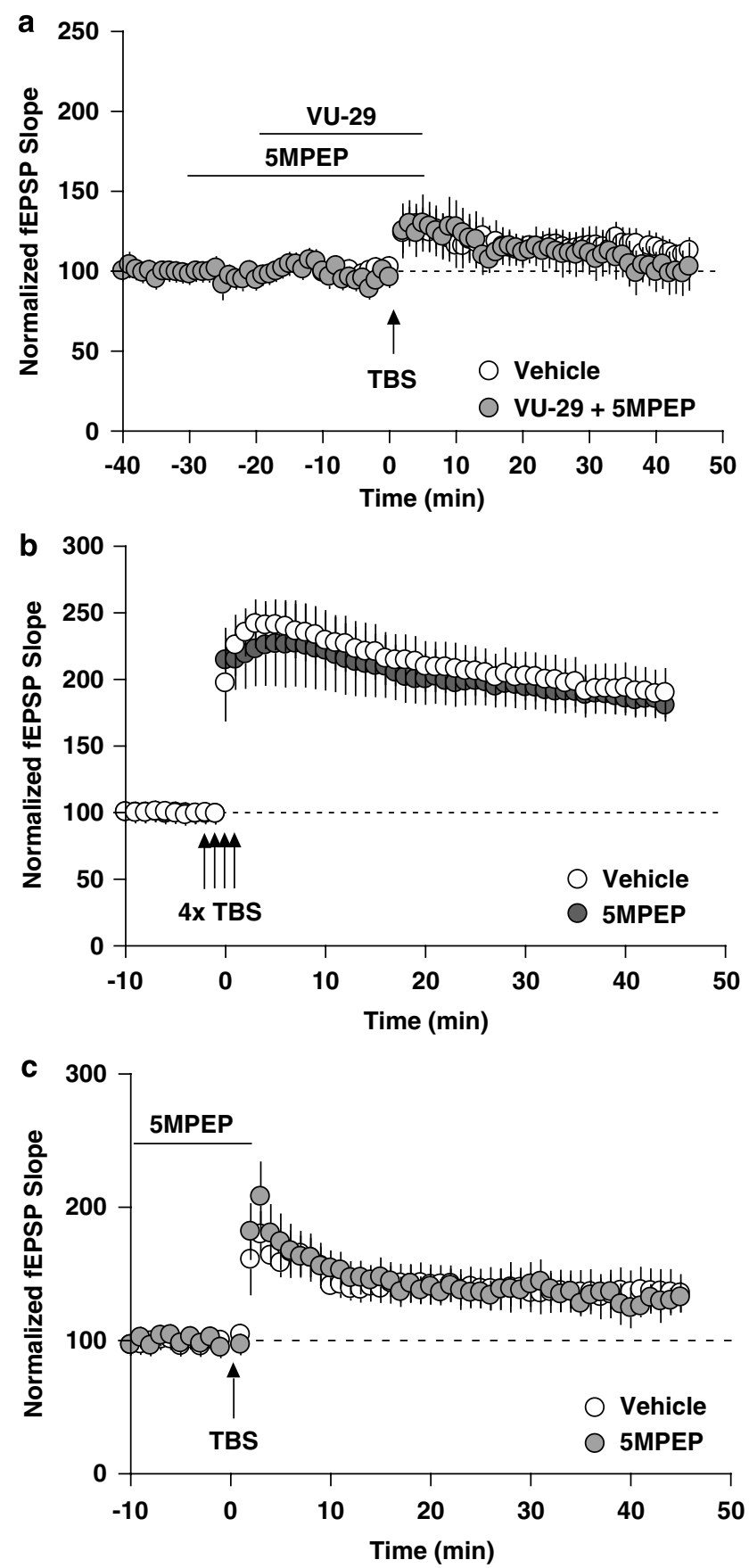

Figure 3 Potentiation of LTP by VU-29 is blocked by the mGluR5 neutral allosteric modulator 5MPEP. (a) Pre-incubation of $100 \mu \mathrm{M}$ 5MPEP completely inhibited VU-29-facilitated TBS-induced LTP back to vehicle control $(n=8 ; p<0.05)$. (b) $10 \mathrm{~Hz}$ TBS-induced LTP was not altered by the pre-incubation of $100 \mu$ M 5 MPEP $(n=8 ; p>0.05)$. (c) Threshold TBSinduced LTP was not altered by pre-incubation of I $00 \mu$ M 5MPEP $(n=5$; $p>0.05)$. Error bars represent SEM.

of fEPSP slopes $(93 \pm 4.15 \%$ of baseline, $n=10)$ measured 80-90 min following washout of DHPG (Figure 5a). Based on these findings, we chose to use $25 \mu \mathrm{M}$ DHPG for all subsequent experiments. Twenty-minute pretreatment of slices with VU-29 $(500 \mathrm{nM})$ did not potentiate the effects of $25 \mu \mathrm{M}$ DHPG (84 $\pm 6 \%$ of baseline in the presence of $500 \mathrm{nM}$ VU-29, $n=6 ; 89.4 \pm 2.9 \%$ of baseline in the absence of $500 \mathrm{nM}$ VU-29, $n=9$ ). We therefore increased the concen- tration of VU-29 to $1 \mu \mathrm{M}$ and found that prior application of this higher concentration resulted in a significant enhancement of the long-term depression of synaptic transmission induced by DHPG, but had no effect on the initial acute depression (Figure 5b; Acute: $64.2 \pm 3.3 \%$ of baseline in the absence of VU-29; $53.6 \pm 3.5 \%$ of baseline in the presence of VU-29, $p>0.05$; LTD: $93 \pm 4.15 \%$ of baseline in the absence of VU-29, $n=10 ; 70.63 \pm 4.1 \%$ of baseline in the presence of VU-29, $n=4, p<0.01)$. As is the case for VU-29 potentiation of threshold LTP, the neutral allosteric modulator 5MPEP completely blocked the ability of VU-29 to potentiate DHPG-induced LTD (Figure $5 \mathrm{c} ; 70.63 \pm 4.1 \%$ of baseline in the presence of VU-29, $n=4 ; 89.4 \pm 2.9 \%$ of baseline in the absence of VU-29, $n=3, p<0.05)$.

Previous studies indicate that the MAP kinase, ERK1/2, is phosphorylated upon induction of DHPG-LTD in the CA1 region of hippocampal slices (Berkeley and Levey, 2003; Gallagher et al, 2004; Banko et al, 2006) and that inhibitors of ERK1/2 signaling inhibit DHPG-LTD (Gallagher et al, 2004; Banko et al, 2006). These data, coupled with findings that mGluR5 PAMs potentiate mGluR5-induced ERK1/2 phosphorylation discussed above suggest that potentiation of ERK1/2 phosphorylation may be important for mGluR5 PAM enhancement of DHPG-LTD. To test the hypothesis that ERK1/2 phosphorylation is required for the enhancement of DHPG-LTD by VU-29, we performed extracellular field potential recordings in the presence of the MEK inhibitor, U0126. Prior treatment of the slice with U0126 $(20 \mu \mathrm{M})$ significantly inhibited the ability of VU-29 $(1 \mu \mathrm{M})$ to enhance LTD induced by DHPG $(25 \mu \mathrm{M}$ ) (Figure $5 \mathrm{~d}$; $67.2 \pm 5.4 \%$ of baseline in the absence of U0126, $n=4$; $90.6 \pm 5.7 \%$ of baseline in the presence of U0126, $n=4$, $p<0.05)$. Taken together, these data suggest a mechanistic link between enhancement of the MEK/ERK pathway and the ability of mGluR5 PAMs to enhance mGluR-LTD.

\section{VU-29 Potentiates Stimulus-Induced NMDA Receptor- Independent LTD}

Paired-pulse low-frequency stimulation (PP-LFS) induces a form of LTD that is independent of NMDA receptor activation (Kemp and Bashir, 1997, 1999; Huber et al, 2000; Kemp et al, 2000; Kumar and Foster, 2007). Initial studies using the broad-spectrum mGluR antagonist LY341495 suggested that this form of synaptically evoked LTD is dependent on mGluR activation (Bortolotto et al, 1999; Huber et al, 2000; Nosyreva and Huber, 2005). If this stimulus-induced LTD is mechanistically similar to DHPGinduced LTD and mediated by activation of mGluR5, VU-29 may potentiate the LTD response to PP-LFS stimulation. We therefore performed experiments to determine the effect of selective potentiation of mGluR 5 by VU-29 on synaptically evoked LTD. Consistent with previous reports, PP-LFS induced a persistent depression of synaptic transmission at the SC-CA1 synapse that was somewhat smaller than the maximal LTD induced by DHPG (Figure 6a). Interestingly, PP-LFS-induced LTD was significantly enhanced by perfusion with VU-29 $(1 \mu \mathrm{M})$ (Figure $6 \mathrm{a} ; 84.6 \pm 3.6 \%$ of baseline in the absence of VU-29, $n=6 ; 70.8 \pm 5.3 \%$ of baseline in the presence of VU-29, $n=7, p<0.05)$.

Although mGluR-LTD is independent of NMDA receptor activation, a distinct form of LTD has also been described at 

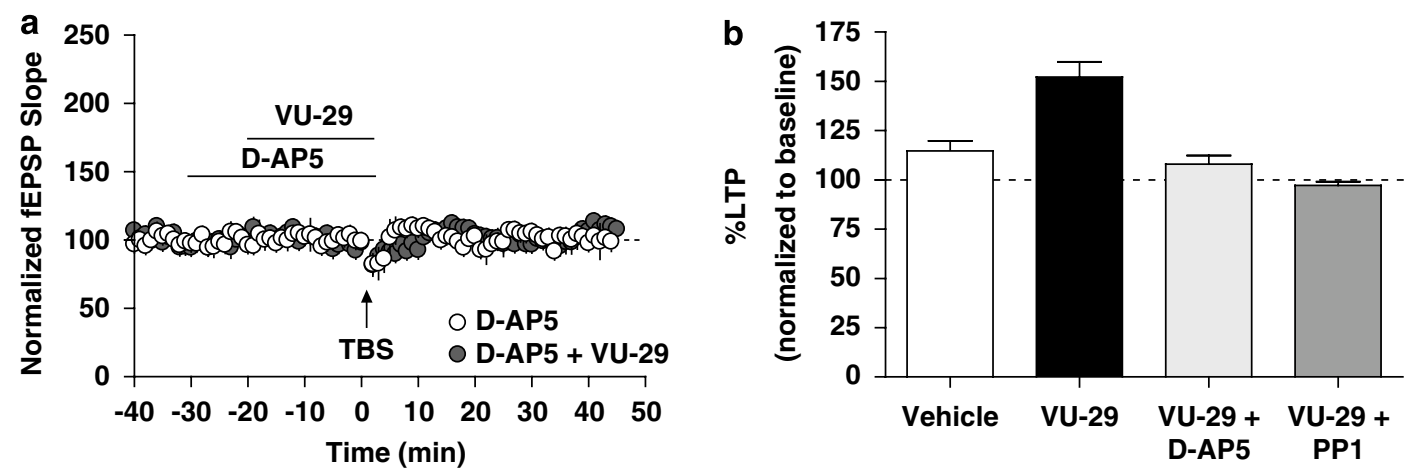

Figure 4 The NMDA receptor antagonist, D-AP5, and the Src-family kinase inhibitor, PP I, block VU-29-facilitated LTP of fEPSPS in rat hippocampal CA I region. (a) $50 \mu$ M D-AP5 ( $n=8$ ) completely blocked TBS-induced LTP in the presence of VU-29 ( $p>0.05$ compared to vehicle-treated slices). (b) Bar graph depicting percent LTP induced by threshold TBS stimulation in the presence of VU-29 and $50 \mu \mathrm{M}$ D-AP5 $(n=8)$ or $20 \mu \mathrm{M}$ PP I (n=7). Error bars represent SEM.
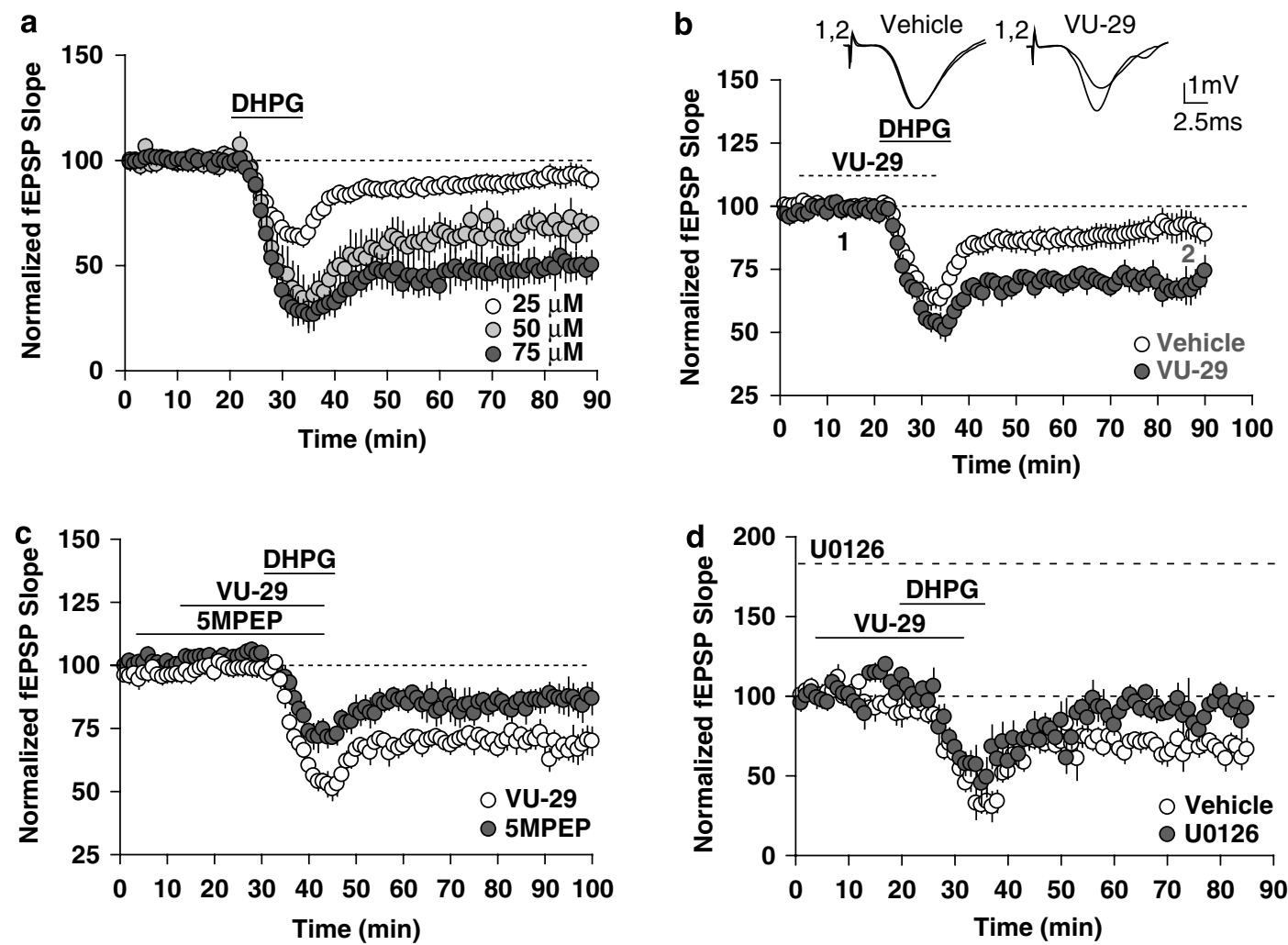

Figure 5 VU-29 potentiates chemically induced mGluR-LTD in area CAI of the rat hippocampus. (a) Field EPSPs are reduced upon addition of the group I mGluR agonist, DHPG, in a concentration-dependent manner. (b) In control slices, $25 \mu$ M DHPG induced a modest level of LTD that was significantly enhanced in slices pre-incubated with I $\mu \mathrm{MVU}-29(n=4 ; p<0.05)$, while having no effect on acute depression $(n=4-6 ; p>0.05)$. (c) Preincubation of the slice with $100 \mu \mathrm{M}$ 5MPEP selectively inhibits the ability of VU-29 (I $\mu \mathrm{M})$ to enhance DHPG-LTD $(n=3-4$; $p<0.05)$ while having no effect on DHPG-LTD by itself $(n=3 ; p>0.05$ compared with DHPG alone). (d) Pre-incubation of the slice with $20 \mu M$ of the MEK inhibitor, U0I26, inhibits the ability of VU-29 ( $\mid \mu M)$ to enhance DHPG-LTD $(n=3-4, p<0.05)$. Error bars represent SEM.

the SC-CA1 synapse that is clearly dependent on NMDA receptor activation (Mulkey and Malenka, 1992). This NMDA receptor-dependent LTD is induced by a distinct stimulus protocol that includes LFS without the pairedpulse stimulation used for induction of mGluR-LTD. However, as discussed above, mGluR5 activation potentiates NMDA receptor currents and mGluR5 PAMs enhance this effect (O'Brien et al, 2004). Thus, it is possible that VU-29 could potentiate NMDA receptor-dependent LTD in a manner similar to potentiation of NMDA receptordependent LTP by threshold TBS. If so, this could contribute to the enhancement seen during PP-LFS-induced LTD. However, in contrast to the effects of VU-29 on threshold TBS-LTP, enhancement of PP-LFS LTD persists in the presence of the NMDA receptor antagonist D-AP5 (Figure $6 \mathrm{~b} ; 90.7 \pm 2.2 \%$ of baseline in the absence of VU-29 $n=5 ; 80.5 \pm 1 \%$ of baseline in the presence of VU-29, $n=5$, $p<0.01)$. This is consistent with previous results showing 

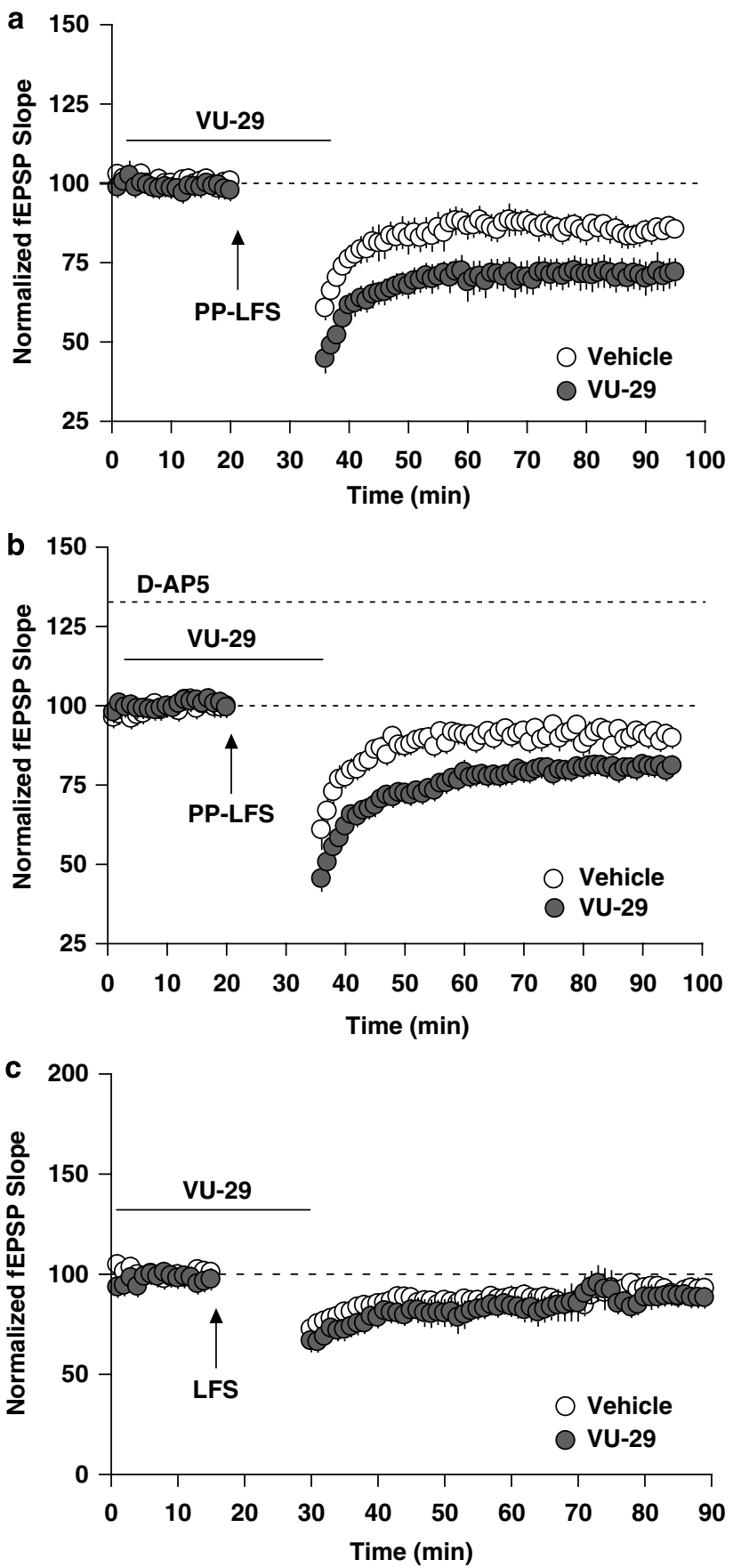

Figure 6 Selective enhancement of mGluR5 receptor signaling significantly increases stimulus induced mGluR-LTD. (a) Paired-pulse lowfrequency stimulation induces mGluR-dependent LTD that was significantly enhanced following pre-incubation of the slice with I $\mu \mathrm{M} \mathrm{VU}-29$ ( $n=6-7$; $p<0.05)$. The enhancement of PP-LFS-induced LTD is independent of NMDA receptor activation and selective enhancement of mGluR5 receptor signaling has no effect on NMDA receptor-dependent LTD. (b) Incubation of the slice with $50 \mu \mathrm{M}$ D-AP5 did not affect the ability of I $\mu$ M VU-29 to potentiate PP-LFS-induced LTD $(n=5 ; p<0.01)$. (c) Lowfrequency stimulation induces NMDA receptor-dependent LTD that is not enhanced in the presence of I $\mu \mathrm{M} \vee \cup-29(n=5-6 ; p>0.05)$. Error bars represent SEM.

that mGluR-LTD is independent of NMDA receptor activation (Kemp and Bashir, 1997, 1999; Huber et al, 2001; Kumar and Foster, 2007). Furthermore, VU-29 does not potentiate LTD induced by the low-frequency stimula- tion protocol used to induce NMDA receptor-dependent LTD. LFS induced a modest long-lasting reduction in the slope of the fEPSP (Figure 6c). Surprisingly, we found that VU-29 was not able to potentiate this NMDA receptordependent form of LTD (Figure $6 c ; 87.07 \pm 4 \%$ of baseline in the absence of VU-29, $n=5 ; 86.88 \pm 6.7 \%$ in the presence of VU-29, $n=4, p>0.05$ ).

\section{VU-29 Does not Alter Induction of Suprathreshold LTP or Reduce Saturated LTP}

The finding that selective potentiation of mGluR5 enhances, afferent stimulation-induced LTD raises the possibility that selectively enhancing mGluR5 at glutamatergic synapses could reduce the LTP response induced by some stimulus protocols. Thus, although VU-29 potentiates threshold TBSinduced LTP, it is conceivable that this compound could dampen the maximal LTP that is induced with suprathreshold TBS stimulation or lead to depotentiation of saturated LTP in response to a stimulus protocol that normally would only lead to LTP. To address these possibilities, we determined the effect of VU-29 on LTP induced by suprathreshold stimulation. Interestingly, VU-29 had no effect on LTP induction when a stimulus protocol (four trains of $10 \mathrm{~Hz}$ TBS) that induces robust LTP in the absence of VU-29 was used (Figure 7; $218 \pm 26 \%$ of baseline at 30 min post TBS in the absence of VU-29, $n=6 ; 192 \pm 13 \%$ of baseline in the presence of VU-29, $n=5, p>0.05)$. To determine whether VU-29 would alter the response to TBS stimulation under conditions of saturated LTP, we applied VU-29 to slices in which a maximal LTP had been previously established. Similar to studies of the response to a single suprathreshold TBS protocol (Figure 7a), VU-29 had no effect on the response to the second suprathreshold TBS (Figure 7b: $191 \pm 14 \%$ of baseline $30-\mathrm{min}$ post TBS, $n=6 ; 185 \pm 7 \%$ of baseline $30-\mathrm{min}$ post TBS in the presence of VU-29, $n=6, p>0.05)$.

\section{A Structurally Distinct mGluR5 PAM Mimics the Effects of VU-29 on Threshold TBS-Induced LTP and DHPG- LTD}

If VU-29-induced potentiation of threshold TBS-LTP and DHPG-LTD is due to selective potentiation of mGluR5 responses, it should be mimicked by a structurally distinct mGluR5 PAM. A novel mGluR5-selective PAM, termed ADX47273 that is structurally unrelated to VU-29 has recently been identified (Le Poul et al, 2005; de Paulis et al, 2006; Liu et al, 2008). This provides an excellent additional tool to verify the effects of mGluR5 PAMs on LTP and LTD. In addition, ADX47273 is systemically active when dosed intraperitoneally and activates mGluR5-mediated increases in ERK1/2 phosphorylation in vivo, making it a useful compound for behavioral studies (Liu et al, 2008). We and others (Liu et al, 2008) have established a protocol for synthesis of ADX47273 and characterized this compound to verify that it is a selective mGluR5 PAM (see Supplementary Figure S4). In previous studies, we rigorously characterized DHPG-induced calcium mobilization in secondary cultured rat cortical astrocytes and found that this response is exclusively mediated by mGluR5 (Peavy et al, 2002) and that mGluR5 PAMs potentiate this response (Rodriguez 

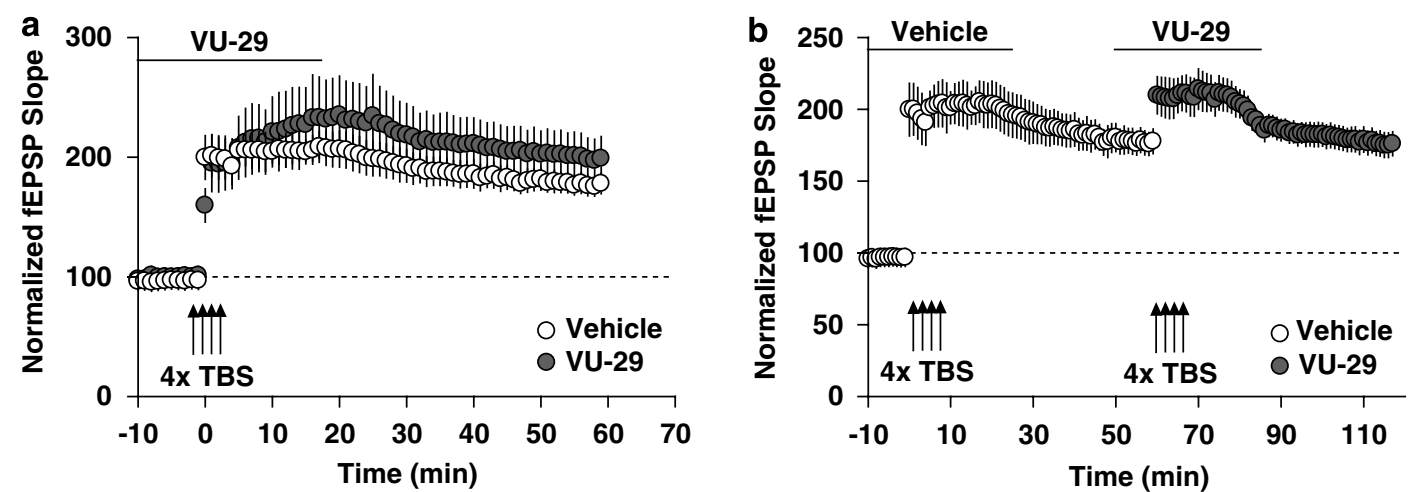

Figure 7 VU-29-facilitated LTP shares similar mechanisms as TBS-induced LTP in area CAI of the hippocampus. (a) $500 \mathrm{nM}$ VU-29 did not alter LTP induced by a suprathreshold TBS protocol that induces robust LTP. In control slices, a $4 \times 100 \mathrm{~Hz}$ TBS-induced robust LTP. The same stimulation in the

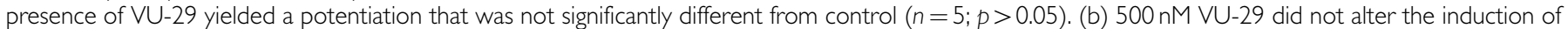
LTP by a suprathreshold TBS protocol in slices in which LTP was previously fully saturated. LTP was induced by four trains of $10 \mathrm{~Hz}$ TBS. After 30 min, the

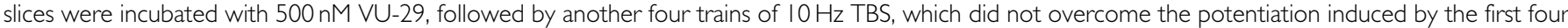
trains of TBS $(n=8 ; p>0.05)$. Error bars represent SEM.

et al, 2005; Zhang et al, 2005; Hemstapat et al, 2006; Chen et al, 2007). ADX47273 induced a robust potentiation of glutamate-induced calcium mobilization in cortical astrocytes in a manner similar to that previously reported for VU-29. Thus, ADX47273 induced a concentration-dependent potentiation of the response to an $\mathrm{EC}_{20}-\mathrm{EC}_{30}$ concentration of glutamate $(300 \mathrm{nM})$ with an $\mathrm{EC}_{50}$ value for ADX47273 of $108 \pm 41 \mathrm{nM}$ (Supplementary Figure S5). Furthermore, ADX47273 $(10 \mu \mathrm{M})$ did not affect the glutamate concentration response curves of mGluR1, mGluR2, or mGluR4 (Supplementary Figure S6; $p>0.05$ ), suggesting that this compound is selective as a PAM for mGluR5 relative to these other mGluR subtypes. Data presented by Liu et al (2008) also confirms the selectivity of ADX47273 as well as demonstrating that ADX47273 competes with $\left[{ }^{3} \mathrm{H}\right]-$ MPEP binding and increases both ERK and CREB phosphorylation in the hippocampus and prefrontal cortex (Liu et al, 2008). Consistent with the effects of VU-29 (Figure 2d), ADX47273 $(10 \mu \mathrm{M})$ induced a significant increase in threshold TBS-induced LTP of fEPSPs in the rat hippocampal CA1 region (see Supplementary Figure S7A; $133 \pm 6 \%$ of baseline at 45 -min post TBS in the absence of ADX47273, $n=9 ; 176 \pm 9 \%$ of baseline at 45 -min post TBS in the presence of ADX47273, $n=12$ ). Although the control level of LTP induced by the threshold-TBS protocol is variable from day to day, the potentiation of thresholdTBS LTP induced by ADX47273 was virtually identical to that induced by threshold-TBS in the presence of VU29. Furthermore, ADX47273 $(10 \mu \mathrm{M})$ induced a significant potentiation of DHPG-induced LTD while having no effect on acute depression (see Supplementary Figure S7B; Acute: $64.2 \pm 3.3 \%$ of baseline in the absence of ADX47273; $63.3 \pm 4.1 \%$ of baseline in the presence of ADX47273, $p>0.05$; LTD: $93 \pm 4.15 \%$ of baseline in the absence of ADX47273, $n=9 ; 71.5 \pm 2.5 \%$ of baseline in the presence of ADX47273, $n=4, p<0.01)$. Taken together, these data provide strong evidence that selective potentiation of mGluR5 responses to endogenous glutamate potentiates threshold TBS-induced LTP and DHPG-induced LTD and will allow further in vivo characterization of mGluR5 PAMs.

\section{mGluR5 PAMs Enhance Hippocampus-Dependent Learning and Memory}

Collectively our data demonstrate a clear ability for mGluR5 PAMs to enhance both hippocampal LTP and LTD in a manner that maintains appropriate activity-dependence of these forms of synaptic plasticity. Theoretically, this ability to enhance both LTP and LTD in a manner that does not shift the balance of these forms of synaptic plasticity could provide an ideal profile for compounds that could be used as cognition-enhancing agents. To directly test the hypothesis that mGluR5 PAMs enhance a hippocampus-dependent form of learning, we performed studies to determine the effects of two systemically active and structurally distinct mGluR5 PAMs, CDPPB and ADX47273, on performance in the Morris water maze, a model of hippocampus-dependent spatial learning. Both CDPPB and ADX47273 (each at a dose of $10 \mathrm{mg} / \mathrm{kg}$ ) enhanced performance in the Morris water maze. This augmented performance is evidenced by significant decreases in the number of days required to reach the acquisition criteria (Figure $8 ; 10.23 \pm 0.54$ in the absence of CDPPB, $n=13 ; 8.5 \pm 0.57$ in the presence of CDPPB, $n=12, p<0.05 ; 8.64 \pm 0.69$ in the absence of ADX 47273, $n=11 ; 6.83 \pm 0.63$ in the presence of ADX47273, $n=12, p<0.05)$ and increased time spent in the target quadrant during the probe trial (Figure 8; $51.5 \pm 3.5 \%$ in the absence of CDPPB, $n=13 ; 63.6 \pm 4.0 \%$ in the presence of CDPPB, $n=12, p<0.05 ; 53.4 \pm 1.9 \%$ in the absence of ADX47273, $n=11 ; 68.1 \pm 2.9 \%$ in the presence of $\mathrm{ADX} 47273, n=12, p<0.05)$. These data, coupled with the unique profile of mGluR5 PAMs on hippocampal synaptic plasticity provide strong support for the hypothesis that mGluR5 PAMs may provide efficacy as a novel approach to enhancing cognitive function in vivo.

\section{DISCUSSION}

In recent years, mGluR5 PAMs have emerged as an exciting new approach that holds promise for treatment of the positive symptoms of schizophrenia (see Conn et al (2009) 

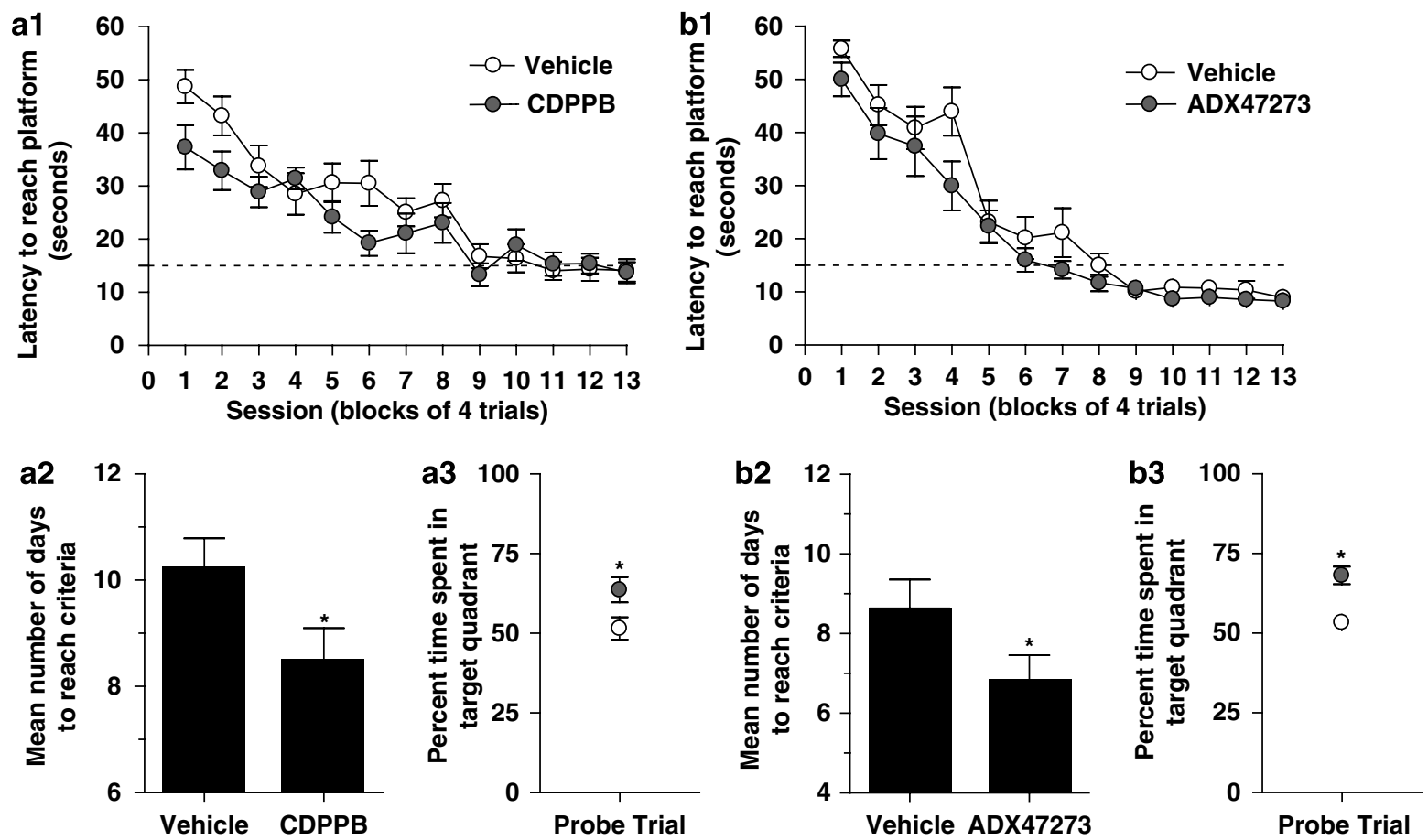

Figure 8 The systemically active mGluR5 PAMs CDPPB and ADX47273 enhance performance in the Morris water maze. (A) CDPPB (I0 mg/kg) decreases latency to reach platform (al), decreases mean number of days to reach criteria ( $\leqslant 15$ s to reach platform; $p<0.05)(a 2)$, and increases time spent in target quadrant during probe trial (a3) $(n=12-13 ; p<0.05)$. (b) ADX47273 $(10 \mathrm{mg} / \mathrm{kg})$ also decreases latency to reach platform (bl), decreases mean number of days to reach criteria $(\leqslant 15 \mathrm{~s}$ to reach platform; $p<0.05)(b 2)$, and increases time spent in target quadrant during probe trial $(b 3)(n=11-12$; $p<0.05) . * 2<0.05$

for review). In addition, increasing evidence suggests that mGluR5 plays an important role in multiple forms of learning and memory and that selective mGluR5 PAMs may provide a novel approach to treat cognitive disturbances in patients with schizophrenia and other disorders that include impaired cognitive function (Campbell et al, 2004; Homayoun et al, 2004; O'Brien et al, 2004; Kinney et al, 2005; Balschun et al, 2006; Lecourtier et al, 2007; Bikbaev et al, 2008; Chan et al, 2008; Darrah et al, 2008).

Abundant evidence suggests that mGluR 5 plays important roles in the induction of both hippocampal LTP (Lu et al, 1997; Cohen et al, 1998; Raymond et al, 2000; Francesconi et al, 2004; Manahan-Vaughan and Braunewell, 2005; Shalin et al, 2006) and LTD (Gasparini et al, 1999; Huber et al, 2001; Faas et al, 2002; Hou and Klann, 2004; Huang et al, 2004; Huang and Hsu, 2006), two opposing long-lasting forms of synaptic plasticity. On the surface, the roles of mGluR5 in these forms of synaptic plasticity are consistent with potential cognition-enhancing effects of these agents. However, the potential for selective actions on these opposing forms of synaptic plasticity raises the possibility that mGluR5 PAMs could lead to inappropriate long-term changes in synaptic responses that are no longer determined by specific patterns or frequencies of synaptic activity. The most important finding of the present studies is that mGluR5 PAMs enhance both LTP and LTD but do not alter the balance or patterns of activity that induce these forms of hippocampal synaptic plasticity. This is in striking contrast to some pathological conditions that include pathophysiological changes in responses to different patterns of afferent stimulation. For instance, in animal models of FXS, induction of mGluR5-dependent LTD is selectively enhanced (Huber et al, 2002; Bear et al, 2004; Nosyreva and Huber, 2006) whereas induction of LTP is impaired (Lauterborn et al, 2007) and this is thought to underlie the cognition-impairment seen in FXS patients. Similar findings have been reported in animal models of intense stress (Chaouloff et al, 2007, 2008) or seizure activity (Kirschstein et al, 2007). The previous findings illustrate the critical need to ensure that agents intended to enhance cognitive function do not induce pathophysiological changes in the balance of these forms of synaptic plasticity.

The unique ability of mGluR5 PAMs to enhance both LTP and LTD and maintain appropriate dependence of both forms of plasticity on specific patterns of synaptic activity, rather than inducing pathophysiological changes in the balance of LTP and LTD, suggests that these agents could have an ideal profile for use as potential cognitionenhancing agents. Consistent with this, we now report direct evidence that two structurally distinct mGluR5 PAMs enhance performance in a model of hippocampusdependent spatial learning. These findings are consistent with multiple studies that have been reported over the past year revealing that mGluR5 PAMs enhance other aspects of cognitive function in animal models (Lecourtier et al, 2007; Chan et al, 2008; Darrah et al, 2008; Liu et al, 2008). For example, the mGluR5 PAM, DFB, induced marked improvement in spatial alternation retention (Balschun et al, 2006). In addition, CDPPB-improved cognitive flexibility in a set-shifting paradigm after disruption with MK-801 (Darrah et al, 2008) and ADX47273 increased object 
exploration in a novel object recognition paradigm (Liu et al, 2008). Thus, our current findings are consistent with an emerging set of behavioral studies and may provide insights into the mechanisms by which mGluR5 PAMs can enhance cognitive function.

In addition to providing critical new insights into the roles of mGluR5 in both LTP and LTD, these findings illustrate a critical potential advantage of PAMs relative to traditional agonists. Unlike mGluR5 PAMs, mGluR5 agonists induce profound LTD and also lead to induction of seizure activity in hippocampal slices and in animal models (Merlin and Wong, 1997; Merlin et al, 1998; Wong et al, 1999; Kingston et al, 2002; Wong et al, 2005). Thus, traditional mGluR5 agonists have the potential to impair cognitive function by selectively inducing LTD and could induce seizure activity. This provides a potential therapeutic advantage to maintaining activity-dependence of mGluR5 signaling by using mGluR5 PAMs that selectively potentiate responses to synaptically released glutamate. Furthermore, it is intriguing that, in contrast to mGluR5 PAMs, the mGluR5-selective agonist CHPG enhances a form of LTD (induced by LFS) that is normally NMDA receptordependent but mGluR5-independent (Neyman and Manahan-Vaughan, 2008).

In summary, when taken together with multiple lines of evidence suggesting that these compounds have antipsychotic efficacy (O'Brien et al, 2003, 2004; Lindsley et al, 2004, 2006; Kinney et al, 2005; Le Poul et al, 2005; de Paulis et al, 2006; Chen et al, 2007, 2008; Liu et al, 2008), the present data provide strong preclinical support for use of selective mGluR5 PAMs as novel therapeutic agents capable of treating both the positive symptoms and cognitive deficits associated with schizophrenia. In addition, these data raise the possibility that mGluR5 PAMs have potential utility in treatment of other disorders that involve impairments in cognitive function.

\section{ACKNOWLEDGEMENTS}

MFO and NLW were supported by PHS grant DA024355.

\section{DISCLOSURE/CONFLICT OF INTEREST}

Dr Conn has received compensation over the past 2 years as a consultant from: Merck and Co., Johnson and Johnson, Hoffman La Roche, GlaxoSmithKline, Lundbeck Research USA, Epix Pharmaceuticals, Invitrogen Life Technologies, Evotec Inc., Addex Pharmaceuticals, Michael J Fox Foundation, Seaside Therapeutics, Cephalon Inc., AstraZeneca USA, NeurOp Inc., Forest Research Institute, LEK Consulting, The Frankel Group, Prestwick Chemical Co., Millipore Corp., Genentech, IMS Health, Primary Insight, and Otsuka. He has received honoraria as a speaker from: University of Toronto, American Society for Bone and Mineral Research, University of Alabama Birmingham, University of Michigan, Southern Research Inst., Harvard Medical School, and the University of North Carolina. He receives research support that includes salary support from NIH, Michael J Fox Foundation, Seaside Therapeutics, and Vanderbilt University. Dr Lindsley consults for Amgen and Eisai and receives research support that includes salary support from
NIH, Michael J Fox, and Seaside Therapeutics. All other authors have nothing to disclose.

\section{REFERENCES}

Andreasen NC (2000). Schizophrenia: the fundamental questions. Brain Res Brain Res Rev 31: 106-112.

Awad H, Hubert GW, Smith Y, Levey AI, Conn PJ (2000). Activation of metabotropic glutamate receptor 5 has direct excitatory effects and potentiates NMDA receptor currents in neurons of the subthalamic nucleus. J Neurosci 20: 7871-7879.

Balschun D, Zuschratter W, Wetzel W (2006). Allosteric enhancement of metabotropic glutamate receptor 5 function promotes spatial memory. Neuroscience 142: 691-702.

Banko JL, Hou L, Poulin F, Sonenberg N, Klann E (2006). Regulation of eukaryotic initiation factor $4 \mathrm{E}$ by converging signaling pathways during metabotropic glutamate receptordependent long-term depression. J Neurosci 26: 2167-2173.

Bear MF, Huber KM, Warren ST (2004). The mGluR theory of fragile X mental retardation. Trends Neurosci 27: 370-377.

Benquet P, Gee CE, Gerber U (2002). Two distinct signaling pathways upregulate NMDA receptor responses via two distinct metabotropic glutamate receptor subtypes. J Neurosci 22: 9679-9686.

Berkeley JL, Levey AI (2003). Cell-specific extracellular signalregulated kinase activation by multiple $G$ protein-coupled receptor families in hippocampus. Mol Pharmacol 63: 128-135.

Berridge MJ, Downes CP, Hanley MR (1982). Lithium amplifies agonist-dependent phosphatidylinositol responses in brain and salivary glands. Biochem J 206: 587-595.

Bikbaev A, Neyman S, Ngomba RT, Conn J, Nicoletti F, Manahan-Vaughan D (2008). MGluR5 mediates the interaction between late-LTP, network activity, and learning. PLOS ONE 3: e2155.

Bortolotto ZA, Fitzjohn SM, Collingridge GL (1999). Roles of metabotropic glutamate receptors in LTP and LTD in the hippocampus. Curr Opin Neurobiol 9: 299-304.

Brody SA, Conquet F, Geyer MA (2004a). Effect of antipsychotic treatment on the prepulse inhibition deficit of mGluR5 knockout mice. Psychopharmacology (Berlin) 172: 187-195.

Brody SA, Dulawa SC, Conquet F, Geyer MA (2004b). Assessment of a prepulse inhibition deficit in a mutant mouse lacking mGlu5 receptors. Mol Psychiatry 9: 35-41.

Camodeca N, Breakwell NA, Rowan MJ, Anwyl R (1999). Induction of LTD by activation of group I mGluR in the dentate gyrus in vitro. Neuropharmacology 38: 1597-1606.

Campbell UC, Lalwani K, Hernandez L, Kinney GG, Conn PJ, Bristow LJ (2004). The mGluR5 antagonist 2-methyl-6-(phenylethynyl)-pyridine (MPEP) potentiates PCP-induced cognitive deficits in rats. Psychopharmacology (Berlin) 175: 310-318.

Chan MH, Chiu PH, Sou JH, Chen HH (2008). Attenuation of ketamine-evoked behavioral responses by mGluR5 positive modulators in mice. Psychopharmacology (Berlin) 198: 141-148.

Chaouloff F, Hemar A, Manzoni O (2007). Acute stress facilitates hippocampal CA1 metabotropic glutamate receptor-dependent long-term depression. J Neurosci 27: 7130-7135.

Chaouloff F, Hemar A, Manzoni O (2008). Local facilitation of hippocampal metabotropic glutamate receptor-dependent longterm depression by corticosterone and dexamethasone. Psychoneuroendocrinology 33: 686-691.

Chen Y, Conn PJ (2008). mGluR5 positive allosteric modulators. Drugs of the Future 33: 355-360.

Chen Y, Goudet C, Pin JP, Conn PJ (2008). N-\{4-Chloro-2-[(1,3dioxo-1,3-dihydro-2H-isoindol-2-yl)methyl]phenyl\}-2-hy droxybenzamide (CPPHA) acts through a novel site as a positive allosteric modulator of group 1 metabotropic glutamate receptors. Mol Pharmacol 73: 909-918. 
Chen Y, Nong Y, Goudet C, Hemstapat K, de Paulis T, Pin JP et al (2007). Interaction of novel positive allosteric modulators of metabotropic glutamate receptor 5 with the negative allosteric antagonist site is required for potentiation of receptor responses. Mol Pharmacol 71: 1389-1398.

Cohen AS, Raymond CR, Abraham WC (1998). Priming of longterm potentiation induced by activation of metabotropic glutamate receptors coupled to phospholipase C. Hippocampus 8: $160-170$.

Collingridge GL, Bliss TV (1995). Memories of NMDA receptors and LTP. Trends Neurosci 18: 54-56.

Conn PJ, Christopoulos A, Lindsley CW (2009). Allosteric modulators of GPCRs: a novel approach for the treatment of CNS disorders. Nat Rev Drug Discov 8: 41-54.

Conn PJ, Lindsley CW, Jones CK (2009). Activation of metabotropic glutamate receptors as a novel approach for the treatment of schizophrenia. Trends Pharmacol Sci 30(1): 25-31.

Conn PJ, Pin JP (1997). Pharmacology and functions of metabotropic glutamate receptors. Annu Rev Pharmacol Toxicol 37: 205-237.

Conn PJ, Sanders-Bush E (1986). Regulation of serotoninstimulated phosphoinositide hydrolysis: relation to the serotonin 5-HT-2 binding site. J Neurosci 6: 3669-3675.

Darrah JM, Stefani MR, Moghaddam B (2008). Interaction of Nmethyl-D-aspartate and group 5 metabotropic glutamate receptors on behavioral flexibility using a novel operant set-shift paradigm. Behav Pharmacol 19: 225-234.

de Paulis T, Hemstapat K, Chen Y, Zhang Y, Saleh S, Alagille D et al (2006). Substituent effects of N-(1,3-diphenyl-1H-pyrazol5 -yl)benzamides on positive allosteric modulation of the metabotropic glutamate-5 receptor in rat cortical astrocytes. J Med Chem 49: 3332-3344.

Doherty AJ, Palmer MJ, Bortolotto ZA, Hargreaves A, Kingston AE, Ornstein PL et al (2000). A novel, competitive $\mathrm{mGlu}(5)$ receptor antagonist (LY344545) blocks DHPG-induced potentiation of NMDA responses but not the induction of LTP in rat hippocampal slices. Br J Pharmacol 131: 239-244.

Doherty AJ, Palmer MJ, Henley JM, Collingridge GL, Jane DE (1997). (RS)-2-chloro-5-hydroxyphenylglycine (CHPG) activates mGlu5, but no mGlu1, receptors expressed in $\mathrm{CHO}$ cells and potentiates NMDA responses in the hippocampus. Neuropharmacology 36: 265-267.

Faas GC, Adwanikar H, Gereau RWt, Saggau P (2002). Modulation of presynaptic calcium transients by metabotropic glutamate receptor activation: a differential role in acute depression of synaptic transmission and long-term depression. J Neurosci 22: 6885-6890.

Fitzjohn SM, Kingston AE, Lodge D, Collingridge GL (1999). DHPG-induced LTD in area CA1 of juvenile rat hippocampus; characterisation and sensitivity to novel mGlu receptor antagonists. Neuropharmacology 38: 1577-1583.

Francesconi W, Cammalleri M, Sanna PP (2004). The metabotropic glutamate receptor 5 is necessary for late-phase long-term potentiation in the hippocampal CA1 region. Brain Res 1022: $12-18$.

Galici R, Jones CK, Hemstapat K, Nong Y, Echemendia NG, Williams LC et al (2006). Biphenyl-indanone A, a positive allosteric modulator of the metabotropic glutamate receptor subtype 2 , has antipsychotic- and anxiolytic-like effects in mice. J Pharmacol Exp Ther 318: 173-185.

Gallagher SM, Daly CA, Bear MF, Huber KM (2004). Extracellular signal-regulated protein kinase activation is required for metabotropic glutamate receptor-dependent long-term depression in hippocampal area CA1. J Neurosci 24: 4859-4864.

Gasparini F, Lingenhohl K, Stoehr N, Flor PJ, Heinrich M, Vranesic I et al (1999). 2-Methyl-6-(phenylethynyl)-pyridine (MPEP), a potent, selective and systemically active mGlu5 receptor antagonist. Neuropharmacology 38: 1493-1503.
Gerber U, Gee CE, Benquet P (2007). Metabotropic glutamate receptors: intracellular signaling pathways. Curr Opin Pharmacol 7: 56-61.

Godfraind JM, Reyniers E, De Boulle K, D’Hooge R, De Deyn PP, Bakker CE et al (1996). Long-term potentiation in the hippocampus of fragile X knockout mice. Am J Med Genet 64: 246-251.

Hemstapat K, de Paulis T, Chen Y, Brady AE, Grover VK, Alagille $D$ et al (2006). A novel class of positive allosteric modulators of metabotropic glutamate receptor subtype 1 interact with a site distinct from that of negative allosteric modulators. $\mathrm{Mol}$ Pharmacol 70: 616-626.

Henry SA, Lehmann-Masten V, Gasparini F, Geyer MA, Markou A (2002). The mGluR5 antagonist MPEP, but not the mGluR2/3 agonist LY314582, augments PCP effects on prepulse inhibition and locomotor activity. Neuropharmacology 43: 1199-1209.

Homayoun H, Stefani MR, Adams BW, Tamagan GD, Moghaddam B (2004). Functional interaction between NMDA and mGlu5 receptors: effects on working memory, instrumental learning, motor behaviors, and dopamine release. Neuropsychopharmacology 29: 1259-1269.

Hou L, Klann E (2004). Activation of the phosphoinositide 3kinase-Akt-mammalian target of rapamycin signaling pathway is required for metabotropic glutamate receptor-dependent longterm depression. J Neurosci 24: 6352-6361.

Huang CC, Hsu KS (2006). Sustained activation of metabotropic glutamate receptor 5 and protein tyrosine phosphatases mediate the expression of (S)-3,5-dihydroxyphenylglycine-induced longterm depression in the hippocampal CA1 region. $J$ Neurochem 96: 179-194.

Huang CC, You JL, Wu MY, Hsu KS (2004). Rap1-induced p38 mitogen-activated protein kinase activation facilitates AMPA receptor trafficking via the GDI.Rab5 complex. Potential role in (S)-3,5-dihydroxyphenylglycene-induced long term depression. J Biol Chem 279: 12286-12292.

Huber KM, Gallagher SM, Warren ST, Bear MF (2002). Altered synaptic plasticity in a mouse model of fragile $\mathrm{X}$ mental retardation. Proc Natl Acad Sci USA 99: 7746-7750.

Huber KM, Kayser MS, Bear MF (2000). Role for rapid dendritic protein synthesis in hippocampal mGluR-dependent long-term depression. Science 288: 1254-1257.

Huber KM, Roder JC, Bear MF (2001). Chemical induction of mGluR5- and protein synthesis - dependent long-term depression in hippocampal area CA1. J Neurophysiol 86: 321-325.

Jia Z, Lu Y, Henderson J, Taverna F, Romano C, Abramow-Newerly $\mathrm{W}$ et al (1998). Selective abolition of the NMDA component of long-term potentiation in mice lacking mGluR5. Learn Mem 5: 331-343.

Johnson MP, Chamberlain M, Kelly GM (1999). Phosphoinositide hydrolysis in vivo with group I metabotropic glutamate receptor agonists. Brain Res 821: 539-545.

Kemp N, Bashir ZI (1997). NMDA receptor-dependent and -independent long-term depression in the CA1 region of the adult rat hippocampus in vitro. Neuropharmacology 36: 397-399.

Kemp N, Bashir ZI (1999). Induction of LTD in the adult hippocampus by the synaptic activation of AMPA/kainate and metabotropic glutamate receptors. Neuropharmacology 38: 495-504.

Kemp N, Bashir ZI (2001). Long-term depression: a cascade of induction and expression mechanisms. Prog Neurobiol 65: 339-365.

Kemp N, McQueen J, Faulkes S, Bashir ZI (2000). Different forms of LTD in the CA1 region of the hippocampus: role of age and stimulus protocol. Eur J Neurosci 12: 360-366.

Kingston AE, Griffey K, Johnson MP, Chamberlain MJ, Kelly G, Tomlinson $\mathrm{R}$ et al (2002). Inhibition of group I metabotropic glutamate receptor responses in vivo in rats by a new generation of carboxyphenylglycine-like amino acid antagonists. Neurosci Lett 330: 127-130. 
Kinney GG, Burno M, Campbell UC, Hernandez LM, Rodriguez D, Bristow LJ et al (2003). Metabotropic glutamate subtype 5 receptors modulate locomotor activity and sensorimotor gating in rodents. J Pharmacol Exp Ther 306: 116-123.

Kinney GG, O’Brien JA, Lemaire W, Burno M, Bickel DJ, Clements MK et al (2005). A novel selective positive allosteric modulator of metabotropic glutamate receptor subtype 5 has in vivo activity and antipsychotic-like effects in rat behavioral models. J Pharmacol Exp Ther 313: 199-206.

Kirschstein T, Bauer M, Muller L, Ruschenschmidt C, Reitze M, Becker AJ et al (2007). Loss of metabotropic glutamate receptordependent long-term depression via downregulation of mGluR5 after status epilepticus. J Neurosci 27: 7696-7704.

Kumar A, Foster TC (2007). Shift in induction mechanisms underlies an age-dependent increase in DHPG-induced synaptic depression at CA3 CA1 synapses. J Neurophysiol 98: 2729-2736.

Larson J, Lynch G (1989). Theta pattern stimulation and the induction of LTP: the sequence in which synapses are stimulated determines the degree to which they potentiate. Brain Res 489: 49-58.

Lauterborn JC, Rex CS, Kramar E, Chen LY, Pandyarajan V, Lynch $\mathrm{G}$ et al (2007). Brain-derived neurotrophic factor rescues synaptic plasticity in a mouse model of fragile $\mathrm{X}$ syndrome. J Neurosci 27: 10685-10694.

Le Poul E, Bessis AS, Lutgens R, Bonnet B, Rocher JP, EppingJordan $\mathrm{M}$ et al (2005). In vitro pharmacological characterisation of selective MgluR5 positive allosteric modulators. 5th International Metabotropic Glutamate Receptors Meeting, Tormina, Italy.

Lecourtier L, Homayoun H, Tamagnan G, Moghaddam B (2007). Positive allosteric modulation of metabotropic glutamate 5 (mGlu5) receptors reverses $N$-Methyl-D-aspartate antagonistinduced alteration of neuronal firing in prefrontal cortex. Biol Psychiatry 62: 739-746.

Li J, Pelletier MR, Perez Velazquez JL, Carlen PL (2002). Reduced cortical synaptic plasticity and GluR1 expression associated with fragile $\mathrm{X}$ mental retardation protein deficiency. Mol Cell Neurosci 19: 138-151.

Lindsley CW, Shipe WD, Wolkenberg SE, Theberge CR, Williams Jr DL, Sur C et al (2006). Progress towards validating the NMDA receptor hypofunction hypothesis of schizophrenia. Curr Top Med Chem 6: 771-785.

Lindsley CW, Wisnoski DD, Leister WH, O’Brien JA, Lemaire W, Williams Jr DL et al (2004). Discovery of positive allosteric modulators for the metabotropic glutamate receptor subtype 5 from a series of $\mathrm{N}$-(1,3-diphenyl-1H- pyrazol-5-yl)benzamides that potentiate receptor function in vivo. J Med Chem 47: 5825-5828.

Liu F, Grauer S, Kelley C, Navarra R, Graf R, Zhang G et al (2008). ADX47273: a novel metabotropic glutamate receptor 5 selective positive allosteric modulator with preclinical antipsychotic-like and pro-cognitive activities. J Pharmacol Exp Ther 327: 827-839.

Lu YM, Jia Z, Janus C, Henderson JT, Gerlai R, Wojtowicz JM et al (1997). Mice lacking metabotropic glutamate receptor 5 show impaired learning and reduced CA1 long-term potentiation (LTP) but normal CA3 LTP. J Neurosci 17: 5196-5205.

Manahan-Vaughan D, Braunewell KH (2005). The metabotropic glutamate receptor, mGluR5, is a key determinant of good and bad spatial learning performance and hippocampal synaptic plasticity. Cereb Cortex 15: 1703-1713.

Mannaioni G, Marino MJ, Valenti O, Traynelis SF, Conn PJ (2001). Metabotropic glutamate receptors 1 and 5 differentially regulate CA1 pyramidal cell function. J Neurosci 21: 5925-5934.

Marino MJ, Conn PJ (2002). Direct and indirect modulation of the N-methyl D-aspartate receptor. Curr Drug Targets CNS Neurol Disord 1: 1-16.
Merlin LR, Bergold PJ, Wong RK (1998). Requirement of protein synthesis for group I mGluR-mediated induction of epileptiform discharges. J Neurophysiol 80: 989-993.

Merlin LR, Wong RK (1997). Role of group I metabotropic glutamate receptors in the patterning of epileptiform activities in vitro. J Neurophysiol 78: 539-544.

Mulkey RM, Malenka RC (1992). Mechanisms underlying induction of homosynaptic long-term depression in area CA1 of the hippocampus. Neuron 9: 967-975.

Neyman S, Manahan-Vaughan D (2008). Metabotropic glutamate receptor 1 (mGluR1) and 5 (mGluR5) regulate late phases of LTP and LTD in the hippocampal CA1 region in vitro. Eur J Neurosci 27: 1345-1352.

Nosyreva ED, Huber KM (2005). Developmental switch in synaptic mechanisms of hippocampal metabotropic glutamate receptordependent long-term depression. J Neurosci 25: 2992-3001.

Nosyreva ED, Huber KM (2006). Metabotropic receptor-dependent long-term depression persists in the absence of protein synthesis in the mouse model of fragile X syndrome. J Neurophysiol 95: 3291-3295.

O’Brien JA, Lemaire W, Chen TB, Chang RS, Jacobson MA, Ha SN et al (2003). A family of highly selective allosteric modulators of the metabotropic glutamate receptor subtype 5. Mol Pharmacol 64: 731-740.

O'Brien JA, Lemaire W, Wittmann M, Jacobson MA, Ha SN, Wisnoski DD et al (2004). A novel selective allosteric modulator potentiates the activity of native metabotropic glutamate receptor subtype 5 in rat forebrain. J Pharmacol Exp Ther 309: 568-577.

Palmer MJ, Irving AJ, Seabrook GR, Jane DE, Collingridge GL (1997). The group I mGlu receptor agonist DHPG induces a novel form of LTD in the CA1 region of the hippocampus. Neuropharmacology 36: 1517-1532.

Paradee W, Melikian HE, Rasmussen DL, Kenneson A, Conn PJ, Warren ST (1999). Fragile X mouse: strain effects of knockout phenotype and evidence suggesting deficient amygdala function. Neuroscience 94: 185-192.

Peavy RD, Chang MS, Sanders-Bush E, Conn PJ (2001). Metabotropic glutamate receptor 5-induced phosphorylation of extracellular signal-regulated kinase in astrocytes depends on transactivation of the epidermal growth factor receptor. J Neurosci 21: 9619-9628.

Peavy RD, Sorensen SD, Conn PJ (2002). Differential regulation of metabotropic glutamate receptor 5-mediated phosphoinositide hydrolysis and extracellular signal-regulated kinase responses by protein kinase $\mathrm{C}$ in cultured astrocytes. J Neurochem 83: 110-118.

Pisani A, Gubellini P, Bonsi P, Conquet F, Picconi B, Centonze D et al (2001). Metabotropic glutamate receptor 5 mediates the potentiation of $\mathrm{N}$-methyl-D-aspartate responses in medium spiny striatal neurons. Neuroscience 106: 579-587.

Raymond CR, Thompson VL, Tate WP, Abraham WC (2000). Metabotropic glutamate receptors trigger homosynaptic protein synthesis to prolong long-term potentiation. J Neurosci 20: 969-976.

Rodriguez AL, Nong Y, Sekaran NK, Alagille D, Tamagnan GD, Conn PJ (2005). A close structural analog of 2-methyl-6(phenylethynyl)-pyridine acts as a neutral allosteric site ligand on metabotropic glutamate receptor subtype 5 and blocks the effects of multiple allosteric modulators. Mol Pharmacol 68: 1793-1802.

Sacaan AI, Santori EM, Rao TS (1998). (S)-4-carboxy-3-hydroxyphenylglycine activates phosphatidyl inositol linked metabotropic glutamate receptors in different brain regions of the neonatal rat. Neurochem Int 32: 77-85.

Shalin SC, Hernandez CM, Dougherty MK, Morrison DK, Sweatt JD (2006). Kinase suppressor of Ras1 compartmentalizes hippocampal signal transduction and subserves synaptic plasticity and memory formation. Neuron 50: 765-779. 
Tan Y, Hori N, Carpenter DO (2003). The mechanism of presynaptic long-term depression mediated by group I metabotropic glutamate receptors. Cell Mol Neurobiol 23: 187-203.

Volk LJ, Daly CA, Huber KM (2006). Differential roles for group 1 mGluR subtypes in induction and expression of chemically induced hippocampal long-term depression. J Neurophysiol 95: 2427-2438.

Wong RK, Bianchi R, Chuang SC, Merlin LR (2005). Group I mGluR-induced epileptogenesis: distinct and overlapping roles of mGluR1 and mGluR5 and implications for antiepileptic drug design. Epilepsy Curr 5: 63-68.

Wong RK, Bianchi R, Taylor GW, Merlin LR (1999). Role of metabotropic glutamate receptors in epilepsy. Adv Neurol 79: 685-698.

Zhang Y, Rodriguez AL, Conn PJ (2005). Allosteric potentiators of metabotropic glutamate receptor subtype 5 have differential effects on different signaling pathways in cortical astrocytes. J Pharmacol Exp Ther 315: 1212-1219.

Supplementary Information accompanies the paper on the Neuropsychopharmacology website (http://www.nature.com/npp) 